\title{
The Study and Analysis of the Effect of the T-shaped Groin Length on the Riprap Stability around the Rotatory Groin of the Rivers
}

\author{
Mohammad Rafie Rafiee ${ }^{* 1}$, Amir Abas Kamanbedast ${ }^{2}$, Roozbeh Aghamajidi ${ }^{3}$ \\ 1- Assistant Professor, Department of water sciences \& engineering, college of agriculture; \\ Jahrom University, Jahrom, I.R. Iran. Postal code: 74137-66171 \\ 2- Assistant Professor, Department of Water Science and Engineering, Ahwaz Branch, \\ Islamic Azad University (IAU), Ahwaz, Iran. \\ 3 - Assistant Professor, Civil Department, Islamic azad university, Sepidan branch, Iran \\ email : roozbeh1381@yahoo.com \\ (*: Corresponding Author, Email: mrrafiee73@gmail.com)
}

\begin{abstract}
Using impermeable groin is a protective method of rivers bank erosion which, in the case of accurate design and implementation, in addition to bank erosion control, leads to recovery and restoration of valuable lands in the rivers' margin. Local scour of the groin nose is one of the design issues in such structures which happens due to narrowing the flow section and existence of the strong vortexes. Due to narrowing of the nose section and occurrence of the downward rotatory flow, local increase of flow velocity leads to the formation of the scour holes of which advancement endangers strength of the structure.VelocityIn this study, the T-shaped breakdown length effect on the riprap stability around the groin in the river was investigated using CCHE2D model.The results were compared with the measured values in the physical model. Results indicated that with the increase of the Froude number, the flow velocity and the shear stress in the groin nose has increased leading to the rise of the index $(\mathrm{Nc})$ and consequently the stability reduction of rip raps. Also, the increase of riprap particles diameter from $9.5 \mathrm{~mm}$ to $12.7 \mathrm{~mm}$ leads to a $13.5 \%$ index $(\mathrm{Nc})$ reduction indicating the increase of ripraps stability with diameter increase. As the groin length increases, there will be no sensible change in the riprap stability but as the length of the groin wing increases, rip raps stability will increase. Results of simulations are very close to the physical model and their average difference is $1.17 \%$. This comparison shows well that CCHE2D software can be used for simulation of the groin and rip raps stability with high precision.
\end{abstract}

Keywords: CCHE2D, Stability, Hydraulic Flow, Simulation, Riprap, groin

\section{Introduction}

Using impermeable groin is a common methodsfor river bank erosion protectionleading to bank erosion control along with recovery and restoration of the valuable lands in the rivers' margin, in case of accurate design and implementation. Groin is a relatively economical and appropriate structure which have been used from the past for different organizational purposes of the river. Extensive application of groins(sometimes accompanied by their deterioration due to the lack of enough knowledge about design issues), has attracted many researchers of the hydraulic science. Although, the groins structures are formed with the aim of sedimentation and avoidance of the bank and margin erosions of rivers and stabilization of rivers situation, they themselves are affected by the erosion phenomena derived from the flow centralization especially in the nose section. In the nose section, local increase of the flow velocity derived from narrowing of the section and the formation of downward rotatory flow, leads to the formation of the scour hole of which advancement endangers the structure strength. According to Lags et al. (2001), the stile breakdown is divided into three groups which are the stile elements erosion, sub-surface erosion, and mass erosion. Erosion of the stile elements is affected by the size of the stile rocks in comparison with the hydrodynamic and disturbance forces, however, the stile slope, stroke, trituration, freezing or wave can also lead to this kind of destruction. Sub-surface erosion happens when the bed materials that are smaller than the stile elements leave the stile void and lead to the stile subsidence. Using filter reduces this kind of erosion to a large extent. Mass erosion happens when a big section of the stile elements or the bed materials collapse as a result of the slippery gravity forces. Based on the experimental results of Chiew (1995), three different mechanisms contribute to the stile instability around the truss including the break derived from cutting, sub-surface demolition and the edge demolition. The break derived from cutting is the stile elements mentionedby Lags et al. (2001). Edge demolition is the moving of the stile elements towards the formed scour pit in the bed sediments leading to the reduction of the conservative effect of the stile. According to Unger and 
Hager (2006), among the three mentioned mechanisms, only sub-surface slide and demolition in the stile around the groin were observed. Regarding that, in the present research, the flow is of a stormy typeand the drag force is calculated as:

$$
F_{D}(t)=\frac{1}{2} C_{D} p u^{2} A(1)
$$

Considering Reynolds analysis for the velocity parameter $(\mathrm{u}=\hat{\mathrm{u}}+\mathrm{u})$ in the stormy flow, the velocity oscillation and average terms which are of the important components in the recognition of the nature of the sediments moving threshold can be reached.

(2) $F_{D}+F_{D}(t)=\frac{1}{2} C_{D} P A\left(U^{2}+\dot{u}^{2}(t)+2 U \dot{u}(t)\right)$

(3) $F_{D}(t)=\frac{1}{2} C_{D}\left(\dot{u}^{2}(t)+2 U \dot{u}(t)-U^{2}\right)$

The amount ofvelocity oscillation rate (ú) can be considered the same as the average velocity term (û). The drag coefficient and the cross section before the flow are two very important parameters in the calculation of the expulsion force (drag. The amount of velocity oscillations is dependent on the selection of these two parameters, however it is notable that flow velocity is very variable in vertical direction adjacent to the bed, effecting the drag coefficient value (Dwivedi, 2010). (Dwivedi, 2010). EsmaeelNejad (2003)- studied the hydraulic input flow to the basins of the deflective dam with a micro-model. In order to prevent the problem of sedimentation in the - basins, he introduced changing of the Chamran basin situation, reduction of the width, along with the increase of the - basin bed level, balance continuously as the most appropriate option. Niknam (2013) simulated the sedimentation process in the Dez dam tank using CCHE2D software and showed that the main coarse particles deposit at the upstream of the dam and fine-grained ones at its downstream. Main sediments due to the high depth of the tank and the low velocity of the flow deposit in the upstream. Marelius and Sinha (1998) showed that at the angle of 40 degrees for a single sheet, the amount of scour around the surface increases but produces the most vortex flow. Abdelazim et al. (2010) estimated lifetime of Aswan dam on the Nile Riverusing the CCHE2D two-dimensional model. In their research, they performed a simulation for $150 \mathrm{~km}$ of the tank length (from $350 \mathrm{~km}$ to $500 \mathrm{~km}$ ) and estimated the lifetime ofof the tank as 254 years. The groin length is selected based on the amount of the width reduction of the main channel of the rivernot exceeding $30 \%$. The distance between the groinsis often selected as a coefficient of their lengths, for example Holland Delft hydraulic laboratory suggested the distance of 1 to 5 times of the groin length. Richardson et al. (1975) has reported the $\frac{S}{L}$ ratio as at least 3 to 4 and utmost 10 to 12 . Charlton (1982) has suggested the $\frac{S}{L}$ ratio for relatively direct ranges as utmost 4 or 4.5 which can increase for internal walls of the turn and decrease for the external walls. Kynvry and Mvvrash (1984) recommended the $\frac{S}{L}$ ratio for protection of walls in the range of 1 to 5 times of the river's length. Peterson (1986) has suggested the $\frac{S}{L}$ ratio for protection of the walls in the ranges of 2 to 6 , for shipping in the ranges of 1.5 to 2 . The T-shaped groin length on the riprap stability around the groin in the shipping rivers using CCHE2D model was evaluated and compared with the measured amounts in the physical model.

Mohammad Ismail Nejad of the year (1381), by creating a micro model hydraulic inlet flow to the basin diversion dam HAMIDIEH studied. His sedimentation in the basin CHAMRAN and AZADEGAN to fix the problem, change the position CHAMRAN the intake, reducing the width and increasing the intake of AZADEGAN on both floor level, has introduced the most suitable option. HadiAliNaqi Zadeh Behbahani in the Year (1387), using physical models to study the hydraulic conditions in the intakes of the angle 90 and 75 degrees. The results show that the size of the deflection angle of deviation flow rate will have a great impact on the so that the angle of inclination of $90^{\circ}$ to $75^{\circ}$ in the same condition, is further deviation than rate. The location intake (in terms of angle deviation), a great impact on sediment deviation ratio so that Angle of $75^{\circ}$ to $90^{\circ}$ in the same hydraulic condition, the ratio of deposits constituted less deviation. Taebi et al (1388), the numerical simulation of flow in a 90 degree arc analyzed using the model CCHE2D respectively. The results showed that the high speed range at the beginning bent to an angle of $50^{\circ}$ arc in the inner wall of the flume and then 50 degrees after to the middle and at the end of the flume is deflected toward the outer wall. Azarang (1388), in their study simulate the hydraulic and sedimentary Karun River in Ahvaz range Farsiat to help one dimensional CCHE2D software is studied. The results of the model CCHE2D, the sedimentation in the range of Ahvaz - Farsiat was estimated at about two and a half million tons per year. Roughanian in year (1389), Karun river flow hydraulic properties may be evaluated using the model CCHE2D and found that in the lateral arch velocity and shear stress than other parts (inner) more. Kamanbedast and Beheshti (1390), using software simulation CCHE2D study the hydraulic characteristics of Karun river flow in the range of Mollasani - Ahvaz. In this study, flow rate -Eshel curve hydrometric stations in Ahvaz, as downstream boundary condition and flow hydrograph Mollasani station with return periods of 2, 10, 25, 50, 100, 200-year as upstream design boundary 
condition and implementation of the unsteady model for maximum water level was achieved. For example, amounts of water surface elevation, velocity, rate per unit width, the resultant shear stress and the Froude number for the 25 years is 16.12 meters, 1.374 meters per second, 7.81 square meters per second, $21.58 \mathrm{Nm}$ per second squared and 0.201 have been met. Marlyvs and Sinha in 1998, showed that at an angle of 40 degrees for a single page, although the amount of scour around page will increase, but most rotational flow is generated. Monadyzadeh in year (1392) Laboratory results dike impact on the flow pattern on the verge of The Agribusiness Dehkhoda the intake using micro model examined. For this purpose micro model of the study area was constructed in the laboratory and testing was done on it. The results show that if dike at distance width of river at intake mouth to distance of 82 meters from the center of the intake to be built in its upstream, dike will have the greatest impact on enters rate the intake and increased 35 percent by volume of water entering the intake. Duan (1998), the CCHE2D model that was called CCHE2D upgraded model and in which characteristics of secondary flows were formulated using CCHE2D model for transformation of two-dimensional to three dimensional flow used. Barakdl and et al (1999) examined ways of increasing the efficiency of submerged vanes. Tests conducted by he showed that the intensity of input seabed sediments into the basin after installing of submerged vanes, when is low which flow rate ratio in the width units basin to flow rate the main channel width, is less than about 0.2 .

\section{Materials and Methods}

\section{Laboratory equipment}

To calibrate and compare the simulations, a laboratory flume made in the Ahvaz Islamic Azad University was used to examine the riprap stability around the T-shaped groin factors in the rivers' arc with the varying dischargesof 1.85, 3.75, 5.08, 6.15 liter per second on the 90 degrees rivers' arc. -Figure 1 shows the entrance and outlet channels of the flume made in a rectangular section with plexiglass sheet walls. The length of the direct entrance channels at the beginning of the flume and the outlet at the end of the flume are 4.5 and 2.5 meters, respectively. The width and height of the flume are also 0.5 and 0.6 meters, respectively and the flume body is constructed with 0.7 meters height above the ground. The floor of the direct entrance passage (to create monotonous and developed flow) has been made of a metal sheet with a thickness of $10 \mathrm{~mm}$ and a length of 4.5 which reduces the effect of the roughness of the wall and also the hydraulic phenomenon in the tank is observable. The outlet passage is also direct, its floor is made of a metal sheet with a $3 \mathrm{~mm}$ thickness and its wall is of plexiglass with $10 \mathrm{~mm}$ thickness and 2.5 meter length. The flume floor is made in the form of a fixed bed and without longitutinalslope. After relaxation of the considered input flow, the flow should enter an arc with 90 degrees angle with external radius of 2 meters. It is made of a plexiglass sheet with a $10 \mathrm{~mm}$ grade so that they can be implemented easily in the arc and for the flume hermetic sealing, the aquarium glue was used.
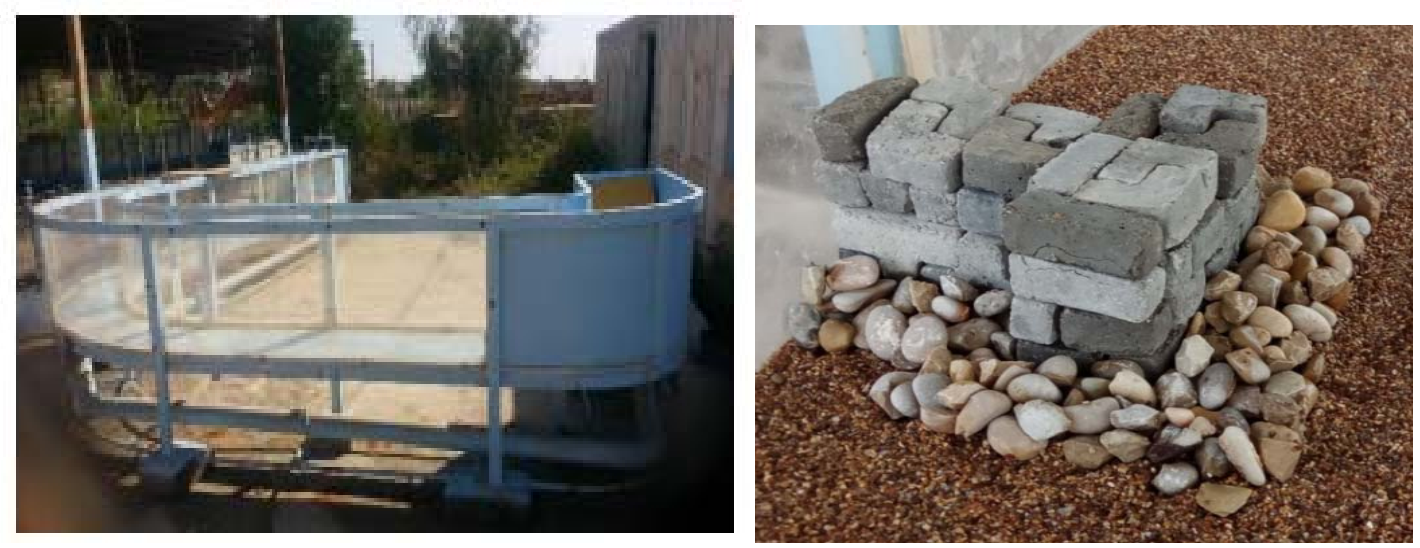

Figure 1: the laboratory flume made for research done 


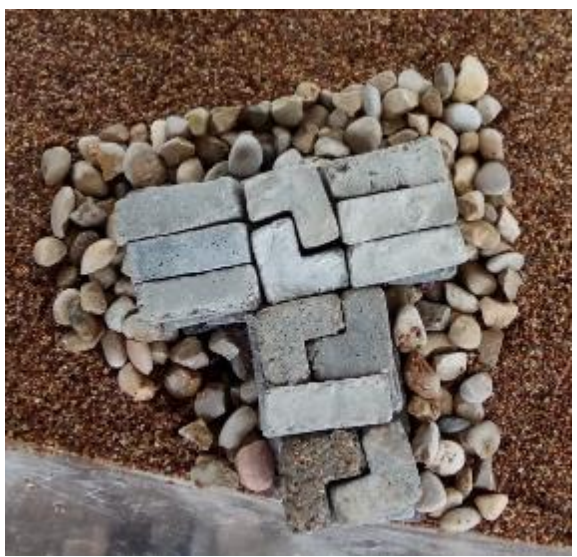

Figure 2: concrete pieces (armor) in the T-shaped groins

Small concrete pieces were put together in a simple and T-shaped form and used as groins (Fig.2) The main channel of the flume consisted of an initial direct channel with 4.5meter length before the arc and an arc with an external radius of 2 meters and a second direct length of 2.5 meters after the arc and a width of 0.5 meter. Water enters a P.V.C tube with 3inches diameter using an EPS pump and enters the tank from under the flume initial tank in the form of a spring. Flow discharge to the flume was fixed by a gate valve installed at the entrance of the main channel.The inflow discharge was assessed manualy by measuring flow depth overa triangular overflow with a 90degrees openingheadinstalled at the canal inlet- After tankage from the basin at different deviation angels, amount of the output water passes the flume over the terminal triangular overflow in order to be measured again which by subtraction of these two rates of flow, the input discharge in different manners of experiments will be obtained. Finally, the outlet flow reaches the terminal tank and will be returned to the system by the installed P.V.C tube under the tank to the underground resource for the laboratory water supply and also the entered discharge to the basin will enter the water supply underground resource again using an appropriate pump. The research data can be classified into two series as:

1) The initial topographic data of the flume and basin

2) The flow data

The initial topographic data are used to define and interpolate the required Mesh network datanecessery for the simulation. The process of sediment transport modeling includes flow simulation in which the process of transmission and distribution of the sediments in the basin are simulated. Actually, the flow and sediment simulation are performed concurrently and in doubles.Flow networking is done by Mesh Generator networking program. The simulation bed consisted of two parts (flume and basin), each part wasgridded in separate blocks, the two blocks were then joined together. Flow data include the initial conditions of the flow, boundary conditions, and flow parameters in the CCHE2D model. The experiments were conducted in 90 scenarios with 5 different rates of flows rates of 2, 4, 6, 8, and 10 liters per second, three groin lengths of 20,40, and 60 percent of the - flume width, two groin wing lengths of 12 and 24 percent of the flume width and three riprap particles diameters of 9.52, 11.2, and $12.7 \mathrm{~mm}$. (Table 1).

Table 1: The main experiments scenarios

\begin{tabular}{|c|c|c|c|c|}
\hline Sum & Riprap particles diameter & The groin wing length & The groin length & discharge \\
\hline 90 & 3 & 2 & 3 & 5 \\
\hline
\end{tabular}

Analysis of the effective factors shows that the stability of the stile and eventually the groin can be dependent on the following factors.

A) Flow regime (Froude number) (4)

$$
F_{r}=\frac{u}{\sqrt{g y}}
$$

B) Hydraulic sediment and stability of bed sediments (Froude number and sediment particles) (5)

$$
F_{r_{d}}=\frac{u}{\sqrt{\left(G_{S}-1\right) g d_{s}}}
$$


C) Groin geometry

(6) $\frac{a}{l}, \frac{a}{a_{0}}$

In which the $a_{0}$ equals to 90 degrees.

DStile geometry including relative diameter and density (stability number)

(7) $N_{C}=\frac{U}{\sqrt{\left(G_{S}-1\right) g d_{R 50}}}$

The index $(\mathrm{Nc})$ was used to examine the ripraps stability.

\section{Results and discussion}

\section{Examination of velocity, shear stress, and the ripraps stability forgroin length of 20 and wing length} of $12 \%$ of the useful flume width.

Regarding table (2) and figures (3) and (4), it can be observed that by increasing the Froude number from 0.032 to 0.171 , the average flow velocity increased from 0.031 to $0.167 \mathrm{~ms}^{-1}$ and the flow velocity near the T-shaped groin nose increased from 0.036 to $0.182 \mathrm{~ms}^{-1}$. By comparing the results of the velocity, it can be understood that the velocity in the groin nose shows 8 percent average increase. Also, with increasing Froude number from 0.032 to 0.171 , the average shear stress rises from 0.01 to $0.278 \mathrm{Nm}^{-2}$ and the shear stress near the T-shaped groin nose increases from 0.012 to $0.31 \mathrm{Nm}^{-2}$. Having compared the results of the shear stress, it can be understood that the cutting nose in the groin nose lead to an average of $8 \%$ increase in shear stress values.

Table 2: Hydraulic results and stability for the groin with the length of 20 and the width of 12 percent

\begin{tabular}{|c|c|c|c|c|c|c|c|}
\hline \multicolumn{3}{|c|}{$\left(\mathrm{D} 50 / Y_{t c}\right)$} & \multicolumn{2}{|c|}{$\begin{array}{l}\text { THE SHEAR STRESS } \\
(و)\end{array}$} & \multicolumn{2}{|c|}{ VELOCITY $(\mathrm{m} / \mathrm{s})$} & \multirow[t]{2}{*}{$\mathrm{Fr}$} \\
\hline 0.127 & 0.112 & 0.095 & Average & $\begin{array}{l}\text { The groin } \\
\text { nose }\end{array}$ & Average & $\begin{array}{l}\text { The groin } \\
\text { nose }\end{array}$ & \\
\hline 0.122 & 0.130 & 0.141 & 0.01 & 0.012 & 0.031 & 0.036 & 0.032 \\
\hline 0.237 & 0.252 & 0.274 & 0.041 & 0.046 & 0.066 & 0.07 & 0.068 \\
\hline 0.362 & 0.386 & 0.419 & 0.096 & 0.107 & 0.102 & 0.107 & 0.103 \\
\hline 0.491 & 0.523 & 0.568 & 0.175 & 0.195 & 0.134 & 0.145 & 0.138 \\
\hline 0.616 & 0.656 & 0.713 & 0.278 & 0.31 & 0.167 & 0.182 & 0.171 \\
\hline
\end{tabular}

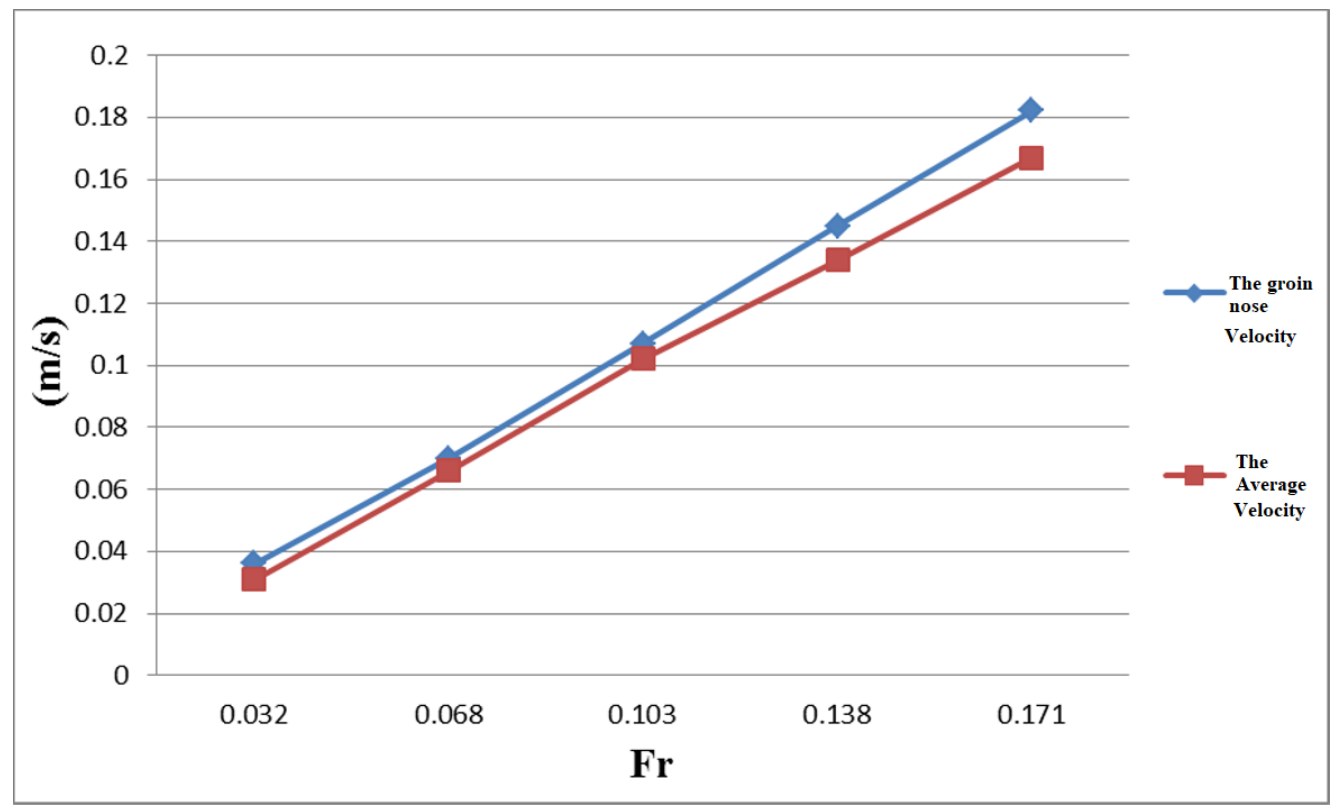

Figure 3: Groin nose and average velocity changes with Fr. for 20mgroin length and wing length of 12 percent 


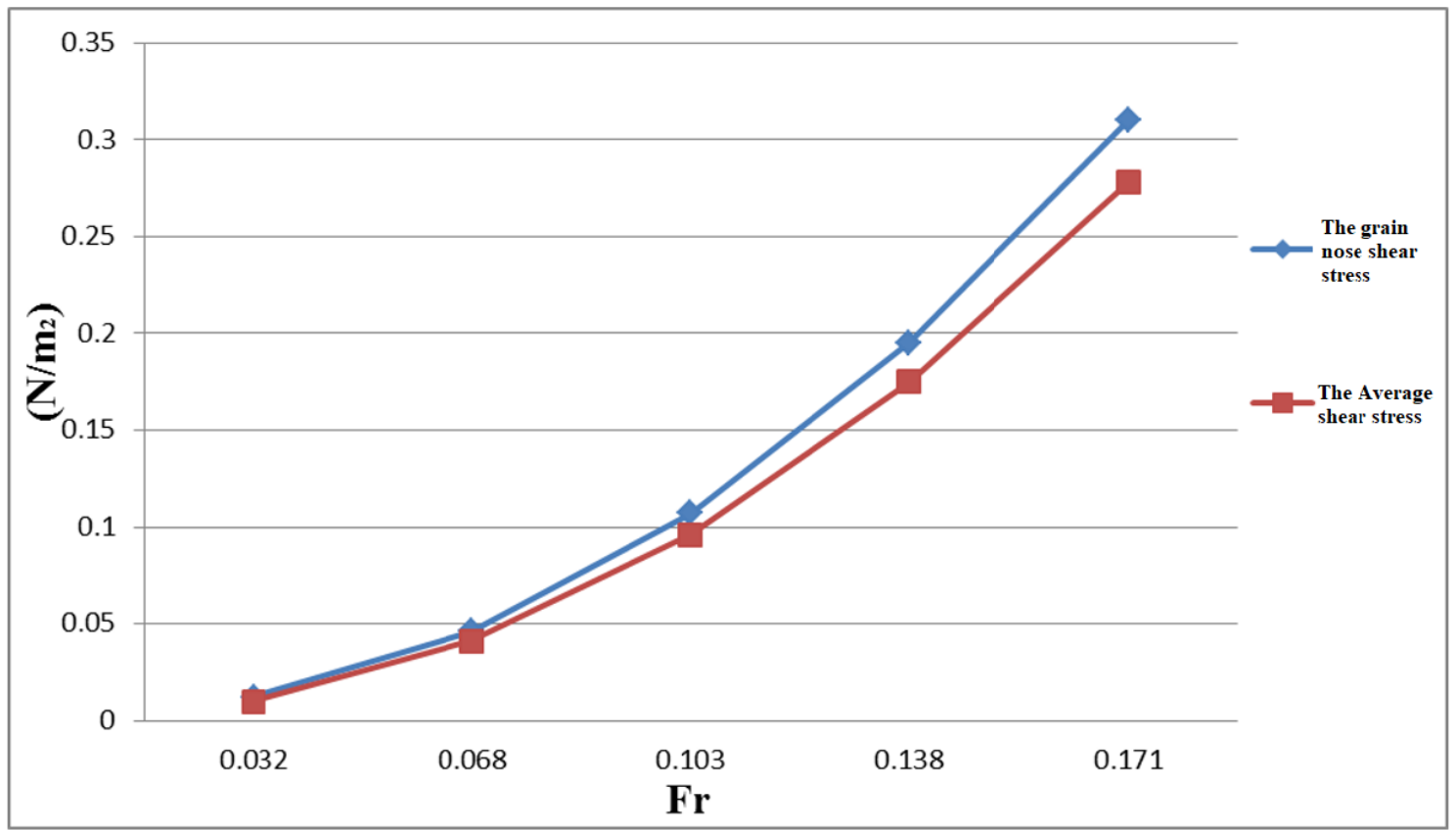

Figure 4: Groin nose and average shear stress changes with Fr. for $20 \mathrm{~m}$ groin length and wing length of $12 \%$

According to figure 5, it can be observed that with the increase of Froude number from 0.032 to 0.171 , the index $(\mathrm{Nc})$ for $9.5 \mathrm{~mm}$ diameter riprap has increased from 0.141 to 0.713 , while such increase was from 0.13 to 0.656 and from 0.122 to 0.616 for $11.2 \mathrm{~mm}$ diameter and $12.7 \mathrm{~mm}$ diameter ripraps, respectively. . Such increase leads to the reduction of ripraps stability. Also, $13.5 \%$ reduction of $\mathrm{Nc}$ index index was met whlieincreasing riprap particles diameter from $9.5 \mathrm{~mm}$ to $12.7 \mathrm{~mm}$. Such reduction shows the increase of the ripraps stability with diameter increase.

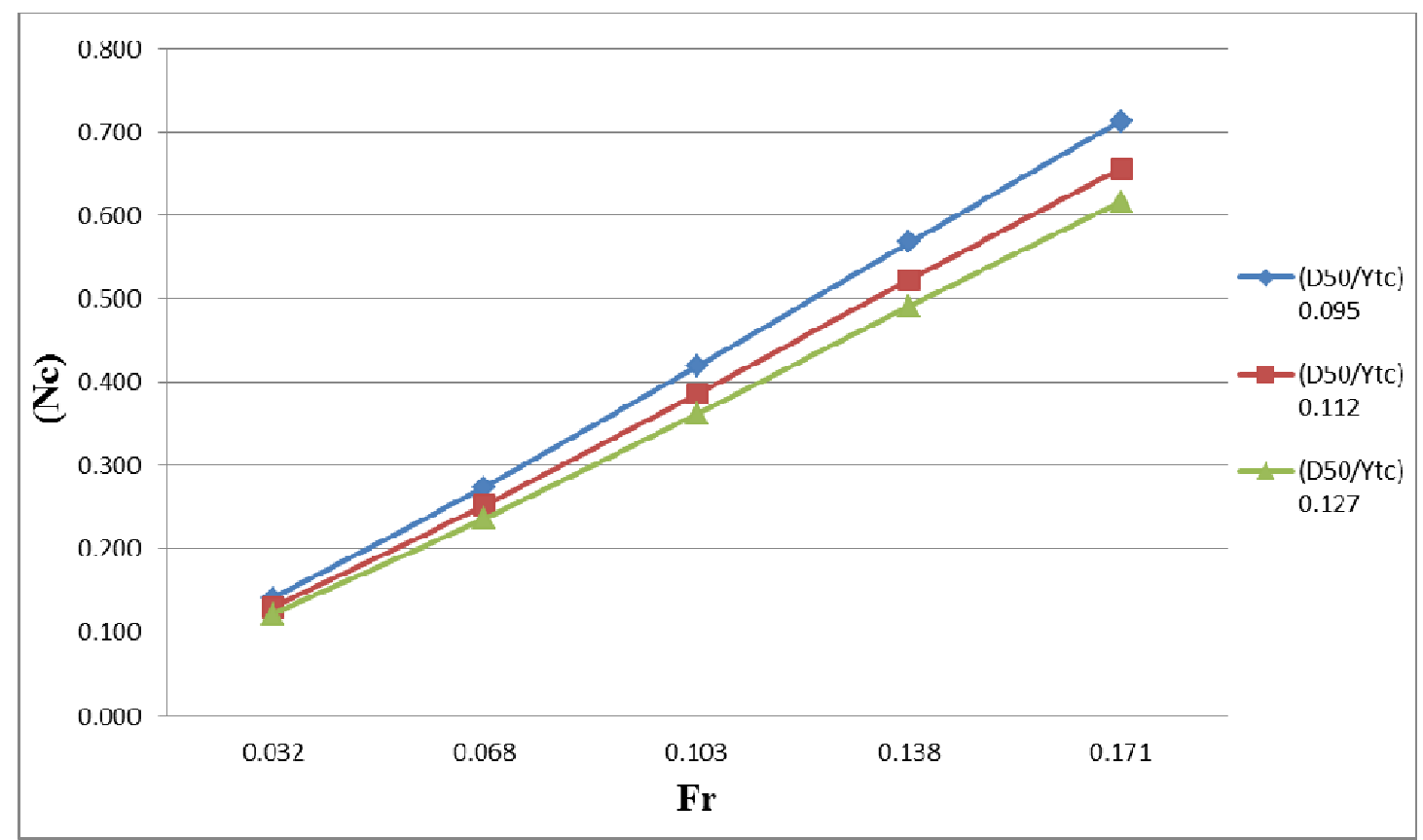

Figure 5: Comparison of the ripraps stability (Nc), groin with the length of $20 \mathrm{~m}$ and the wing length of $12 \%$ for different (D50/Yc) rates 


\section{Examination of velocity, shear stress, and ripraps stability forgroin length of $\mathbf{2 0}$ and the wing length of} $24 \%$ of the useful flume width

Regarding the Table (3) and diagram of the figures (6) and (7), it can be observed that with increasing Froude number from 0.032 to 0.171 , inceases the average flow velocity from 0.031 to $0.167 \mathrm{~ms}^{-1}$ and the flow velocity near the T-shaped groin nose has increased from 0.036 to $0.169 \mathrm{~ms}^{-1}$. A comparison between velocity values shows that velocity values in the groin nose are higher that those of average as $1.8 \%$. Also, by the increase of the Froude number from 0.032 to 0.171 , the average shear stress has increased from 0.01 to $0.278 \mathrm{Nm}^{-2}$ and the shear stress near the T-shaped groin nose has increased from 0.012 to $0.266 \mathrm{Nm}^{-2}$.

Table 3: Hydraulic and stability results for the groin with the length of 20 and the width of 24 percent

\begin{tabular}{|c|c|c|c|c|c|c|c|}
\hline \multicolumn{3}{|c|}{$\left(\mathrm{D} 50 / Y_{t c}\right)$} & \multicolumn{2}{|c|}{ shear stress (واحد) } & \multicolumn{2}{|c|}{ Velocity (m/s) } & \multirow[t]{2}{*}{$\mathrm{Fr}$} \\
\hline 0.127 & 0.112 & 0.095 & Average & $\begin{array}{l}\text { The groin } \\
\text { nose }\end{array}$ & average & $\begin{array}{l}\text { The groin } \\
\text { nose }\end{array}$ & \\
\hline 0.122 & 0.130 & 0.141 & 0.01 & 0.012 & 0.031 & 0.036 & 0.032 \\
\hline 0.230 & 0.245 & 0.266 & 0.041 & 0.043 & 0.066 & 0.068 & 0.068 \\
\hline 0.342 & 0.364 & 0.395 & 0.096 & 0.096 & 0.102 & 0.101 & 0.103 \\
\hline 0.457 & 0.487 & 0.529 & 0.175 & 0.171 & 0.134 & 0.135 & 0.138 \\
\hline 0.572 & 0.609 & 0.662 & 0.278 & 0.266 & 0.167 & 0.169 & 0.171 \\
\hline
\end{tabular}

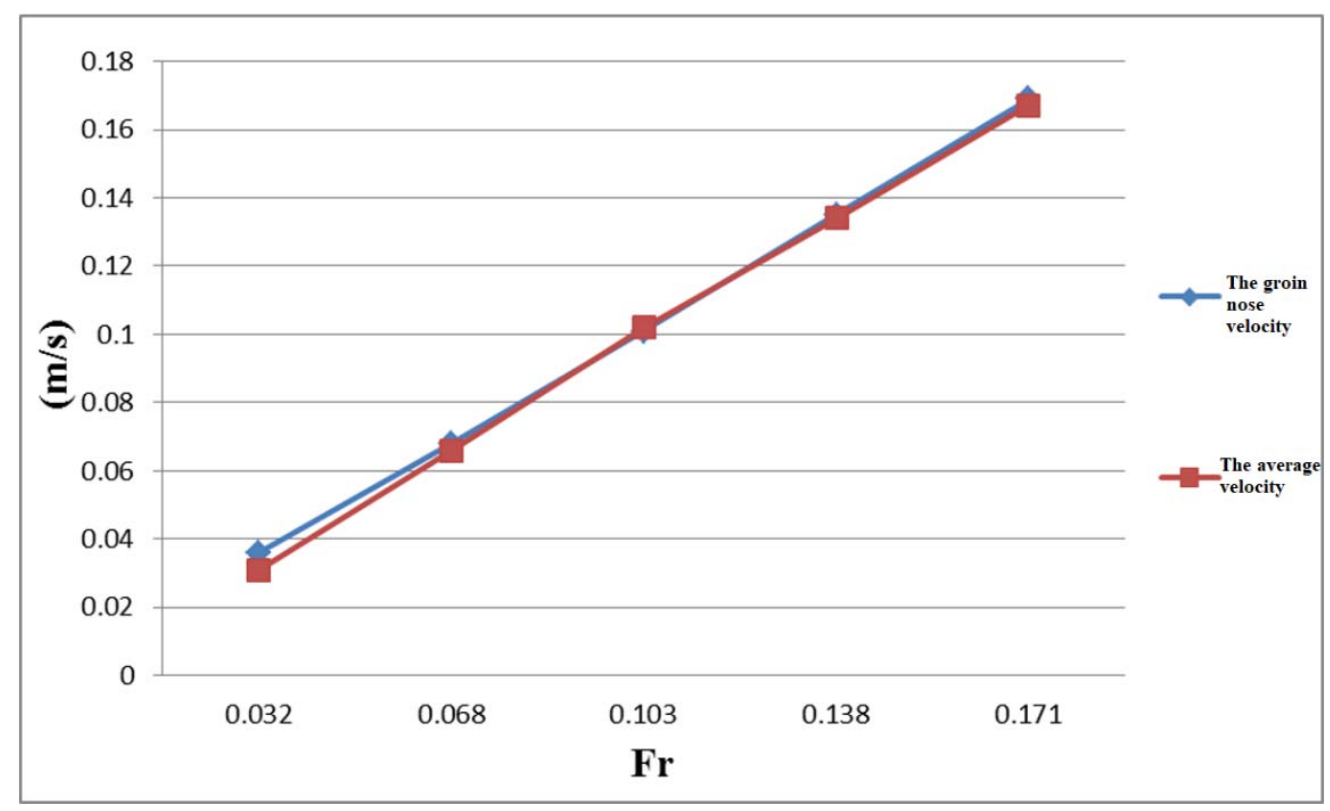

Figure 6: Groin nose and average velocity changes with Fr. for $20 \mathrm{~m}$ groin length and wing length of $24 \%$ 


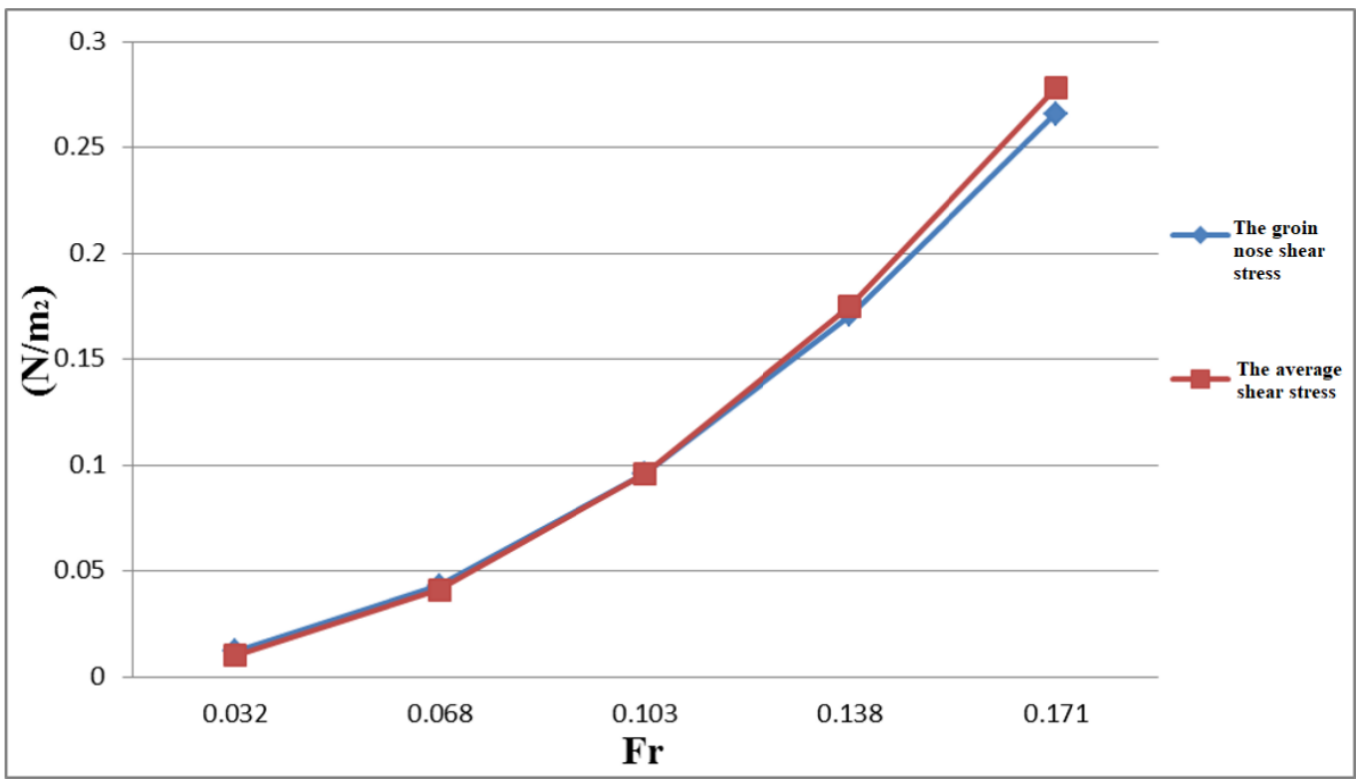

Figure 7: Groin nose and average shear stress changes with Fr. for $20 \mathrm{~m}$ groin length and wing length of $24 \%$

According to Figure (8), by the increase of the Froude number from 0.032 to 0.171 the index (Nc) has increased from 0.141 to 0.662 , from 0.13 to 0.609 and from 0.122 to 0.572 for riprap diameters of $9.5,11.2$ and $12.7 \mathrm{~mm}$, respectively. Such increase leads to the the reduction of the ripraps stability. On the other hand, increasing riprap particles diameter from $9.5 \mathrm{~mm}$ to $12.7 \mathrm{~mm}, 13.5 \%$ reduction was obtained in Nc index values, indicating the ripraps stability increase with diameter.

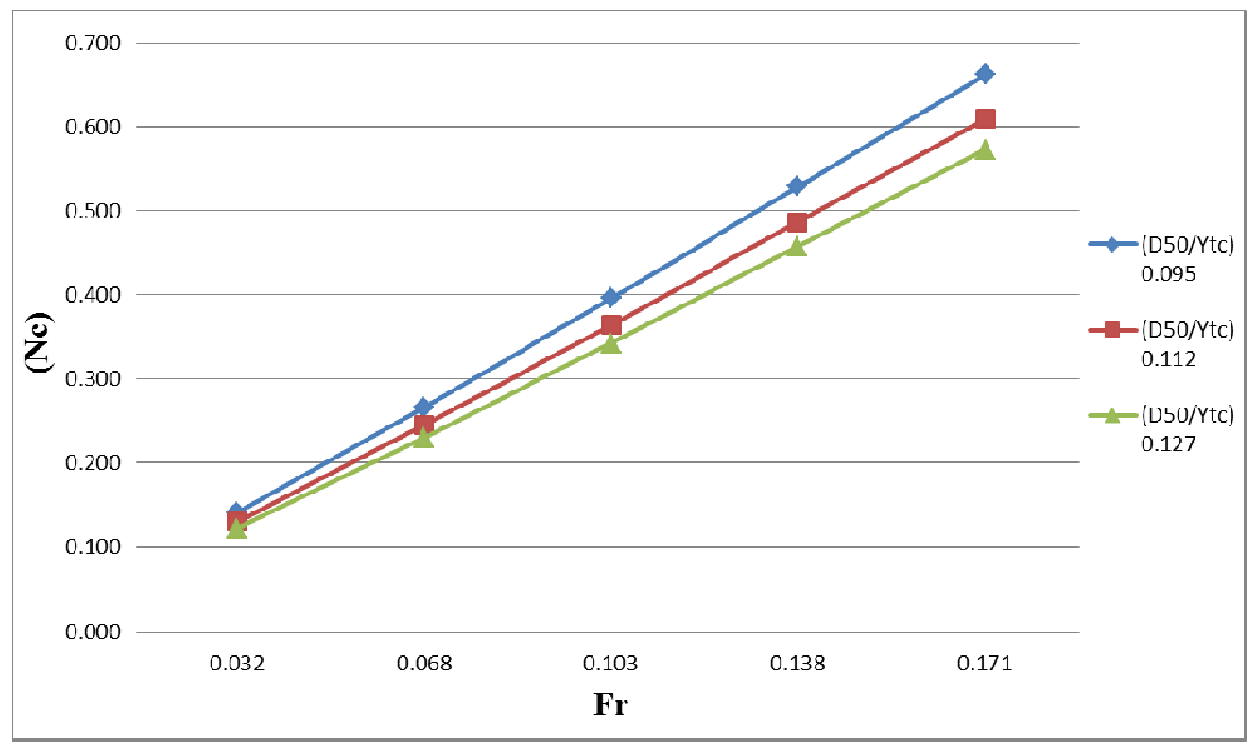

Figure 8: Comparison of the ripraps stability ( $\mathrm{Nc}$ ), groin with the length of $20 \mathrm{~m}$ and the wing length of $24 \%$ for different (D50/Yc) rates

\section{Examination of velocity, shear stress, and ripraps stability for groin length of 40 and the wing length of $12 \%$ of the useful width of the flume}

Table (4) and Figures (9) and (10), indicate that by increasing Froude number from 0.032 to 0.171 , the average flow velocity increases from 0.031 to $0.167 \mathrm{~ms}^{-1}$ and flow velocity near the T-shaped groin nose increases from 0.034 to $0.185 \mathrm{~ms}^{-1}$, while the velocity in the groin nose an average of $7.8 \%$ increase than the average velocity values. Also, increase in Froude number from 0.032 to 0.171 , the average shear stress has increased from 0.01 to $0.278 \mathrm{Nm}^{-2}$, while such obsereved increase was 0.012 to $0.321 \mathrm{Nm}^{-2}$ near the T-shaped groin nose. 
Table 4: Hydraulic and stability results for the groin with the length of 40 and the width of 12 percent

\begin{tabular}{|l|l|l|l|l|l|l|l|}
\hline \multicolumn{3}{|c|}{$\left(\mathrm{D} 50 / Y_{t c}\right)$} & \multicolumn{2}{l|}{ The shear stress (حاح) } & \multicolumn{2}{l|}{ Velocity(m/s) } & Fr \\
\hline 0.127 & 0.112 & 0.095 & Average & $\begin{array}{l}\text { The groin } \\
\text { nose }\end{array}$ & Average & $\begin{array}{l}\text { The groin } \\
\text { nose }\end{array}$ & \\
\hline 0.115 & 0.123 & 0.133 & 0.01 & 0.011 & 0.031 & 0.034 & 0.032 \\
\hline 0.230 & 0.245 & 0.266 & 0.041 & 0.043 & 0.066 & 0.068 & 0.068 \\
\hline 0.359 & 0.382 & 0.359 & 0.096 & 0.105 & 0.102 & 0.106 & 0.103 \\
\hline 0.494 & 0.526 & 0.572 & 0.175 & 0.195 & 0.134 & 0.146 & 0.138 \\
\hline 0.626 & 0.667 & 0.724 & 0.278 & 0.321 & 0.167 & 0.185 & 0.171 \\
\hline
\end{tabular}

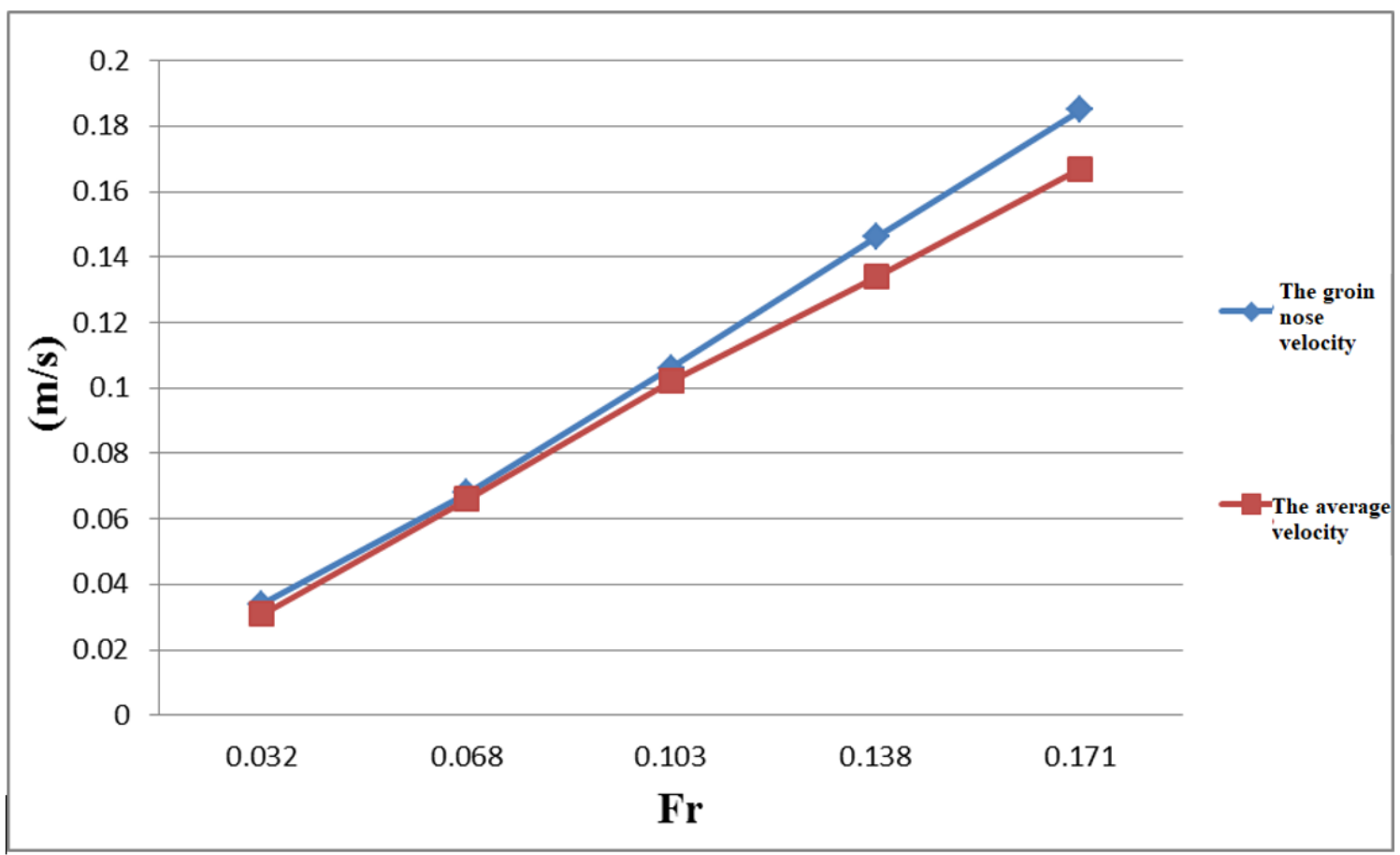

Figure 9: Groin nose and average velocity changes with Fr. for $40 \mathrm{~m}$ groin length and wing length of $12 \%$ 


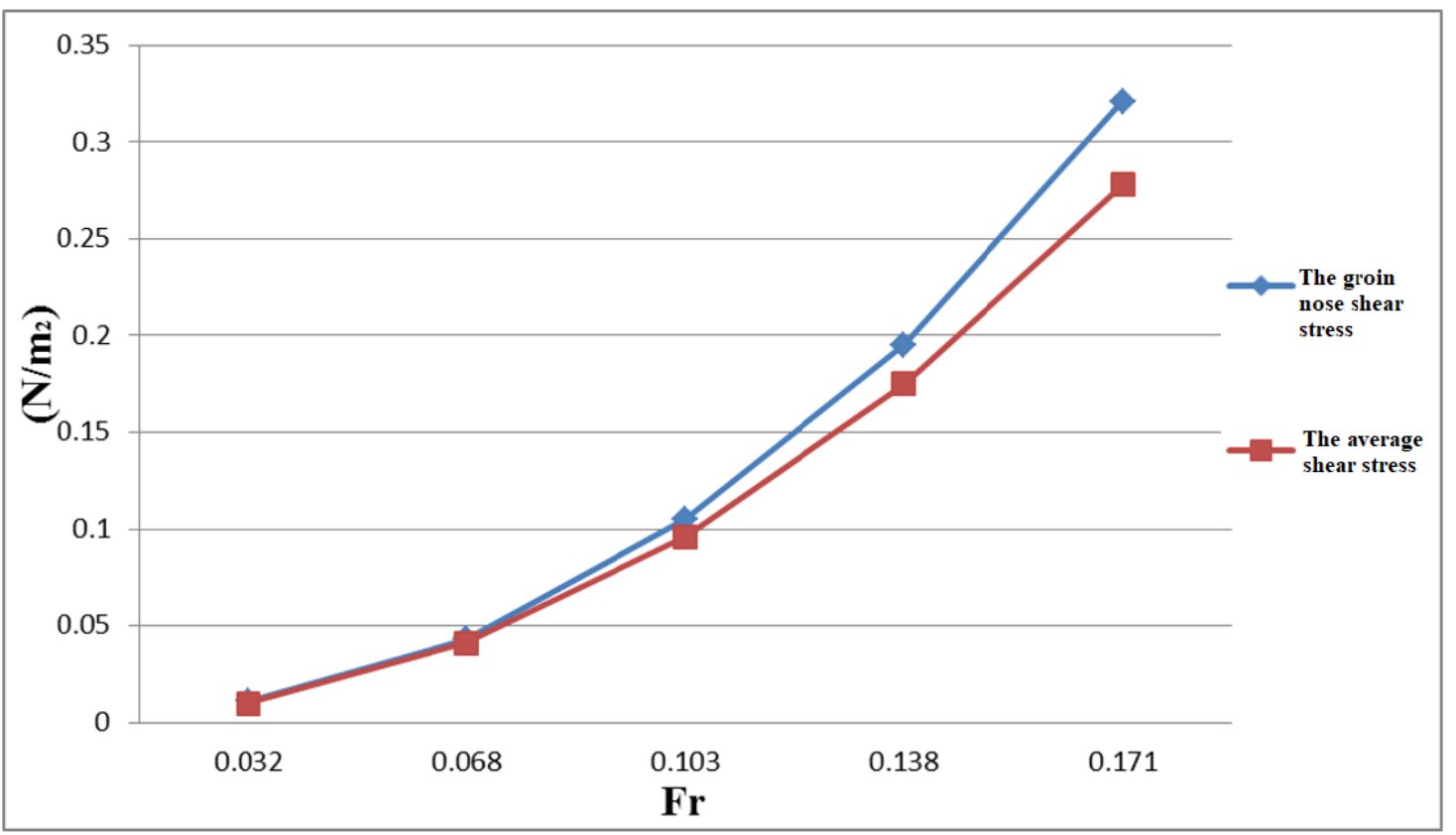

Figure 10: Groin nose and average shear stress changes with Fr. for $40 \mathrm{~m}$ groin length and wing length of $12 \%$

Figure 11 illustrates a comparison between Nc index changes with Froude number for diffenet D50/Yc ratios. Increasing Froude number from 0.032 to 0.171 , the index $(\mathrm{Nc})$ for riprap with $9.5 \mathrm{~mm}$ diameter has increased from 0.133 to 0.724 and the rip rap with a $11.2 \mathrm{~mm}$ diameter from 0.123 to 0.667 and riprap with a $12.7 \mathrm{~mm}$ diameter from 0.115 to 0.626 , indicating reduction of the ripraps stability. Also, by the increase of the riprap

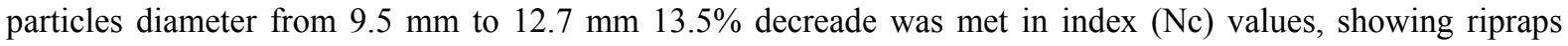
stability increase with diameter increase.

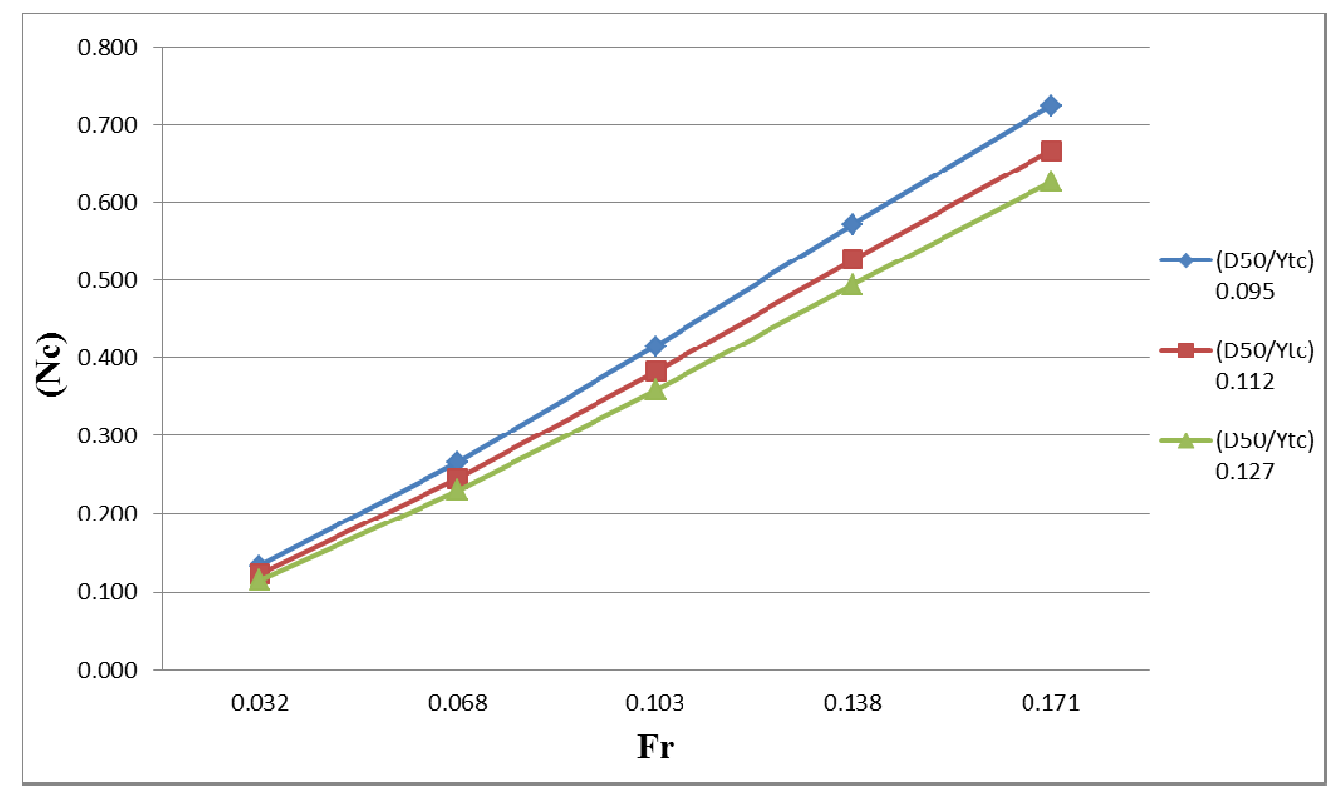

Figure 11: Comparison of the ripraps stability $(\mathrm{Nc})$, groin with the length of $40 \mathrm{~m}$ and the wing length of $12 \%$ for different (D50/Yc) rates

4. Examination of velocity, shear stress, and ripraps stability forgroin length of 40 and wing length of $24 \%$ of the useful flume width

According to the observations reported in Table (5) and Figures (12) and (13), Froude number increase from 0.032 to 0.171 , leads to average flow velocity increase from 0.031 to $0.167 \mathrm{~ms}^{-1}$ and the flow velocity near the T-shaped groin nose increase from 0.035 to $0.175 \mathrm{~ms}^{-1}$. The ratio of average velocity values to those of groin nose was 0.74 . On the other hand, increasing Froude number from 0.032 to 0.171 the average shear stress has increased from 0.01 to $0.278 \mathrm{Nm}^{-2}$ and the shear stress near the T-shaped groin nose has increased from 0.011 to $0.285 \mathrm{Nm}^{-2}$ 
Table 5: Hydraulic and stability results for the groin with the length of 40 and the width of 24 percent

\begin{tabular}{|c|c|c|c|c|c|c|c|}
\hline \multicolumn{3}{|c|}{$\left(\mathrm{D} 50 / Y_{t c}\right)$} & \multicolumn{2}{|c|}{ The shear stress (واحد) } & \multicolumn{2}{|c|}{ Velocity $(\mathrm{m} / \mathrm{s})$} & \multirow[t]{2}{*}{$\mathrm{Fr}$} \\
\hline 0.127 & 0.112 & 0.095 & Average & $\begin{array}{l}\text { The groin } \\
\text { nose }\end{array}$ & Average & $\begin{array}{l}\text { The groin } \\
\text { nose }\end{array}$ & \\
\hline 0.115 & 0.123 & 0.133 & 0.01 & 0.011 & 0.031 & 0.034 & 0.032 \\
\hline 0.230 & 0.245 & 0.266 & 0.041 & 0.043 & 0.066 & 0.068 & 0.068 \\
\hline 0.359 & 0.382 & 0.359 & 0.096 & 0.105 & 0.102 & 0.106 & 0.103 \\
\hline 0.494 & 0.526 & 0.572 & 0.175 & 0.195 & 0.134 & 0.146 & 0.138 \\
\hline 0.626 & 0.667 & 0.724 & 0.278 & 0.321 & 0.167 & 0.185 & 0.171 \\
\hline
\end{tabular}

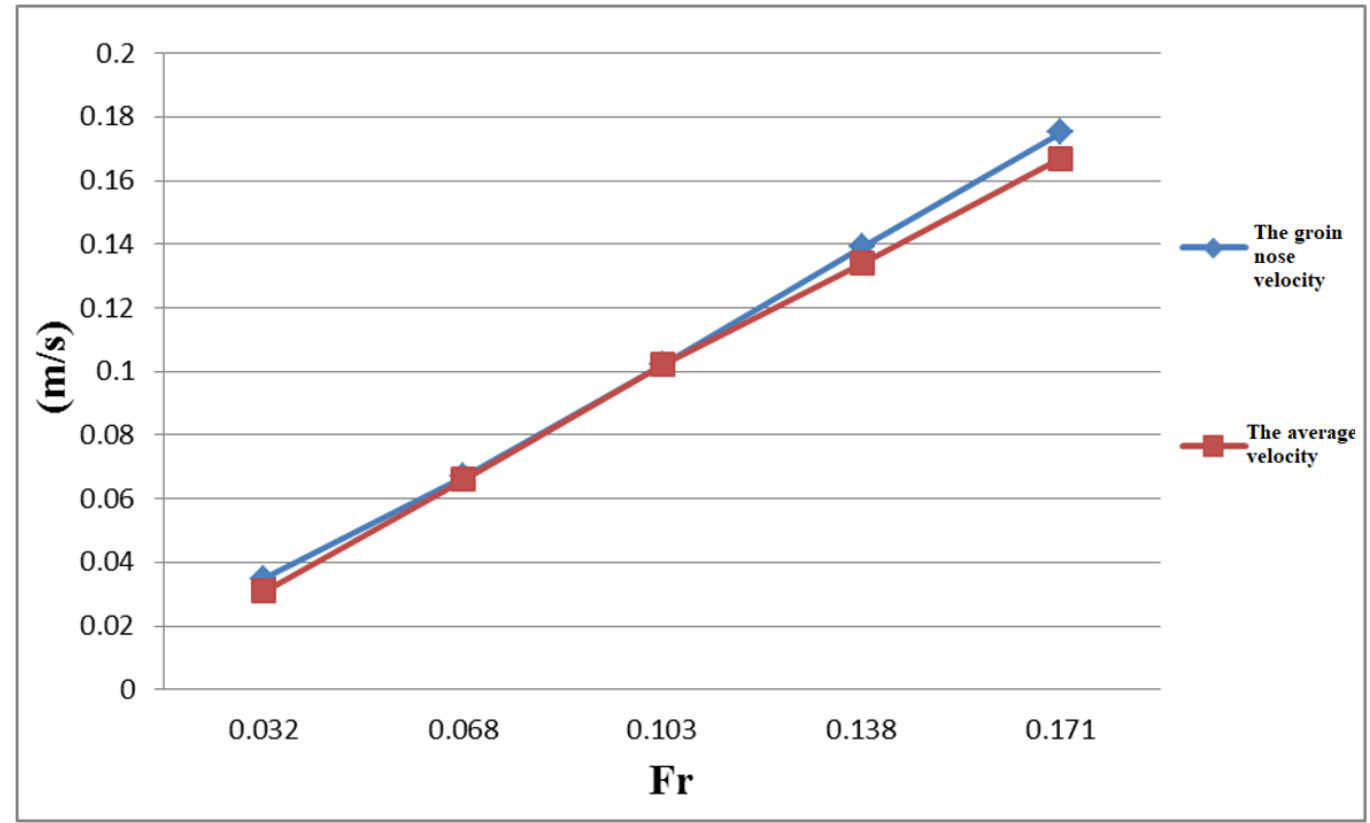

Figure 12: Groin nose and average velocity changes with Fr. for $40 \mathrm{~m}$ groin length and wing length of $24 \%$

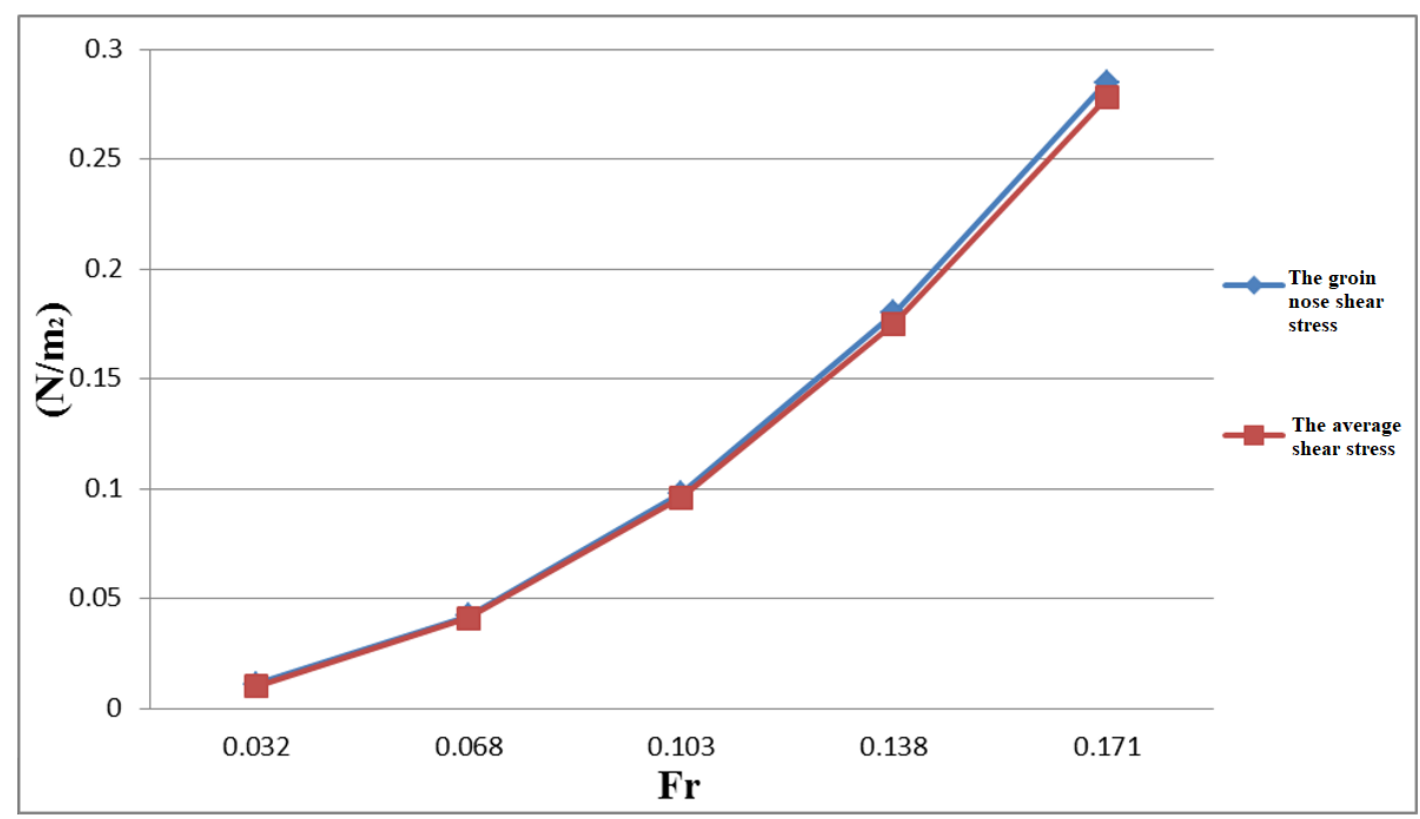

Figure 13: Groin nose and average shear stress changes with Fr. for $40 \mathrm{~m}$ groin length and wing length of $24 \%$ 
Regarding the diagram shown at Figure (14), it can be observed well that by the increase of the Froude number from 0.032 to 0.171 , the index (Nc) for riprap with $9.5 \mathrm{~mm}$ diameter has increased from 0.137 to 0.685 and the rip rap with $11.2 \mathrm{~mm}$ diameter from 0.126 to 0.631 and riprap with $12.7 \mathrm{~mm}$ diameter from 0.119 to 0.593 ,such increase leads to the reduction of the ripraps stability. Also by the increase of the riprap particles diameter from $9.5 \mathrm{~mm}$ to $12.7 \mathrm{~mm} 13.5$ percent index $(\mathrm{Nc})$, reduction was observed.This reduction shows the ripraps stability increase with diameter increase.

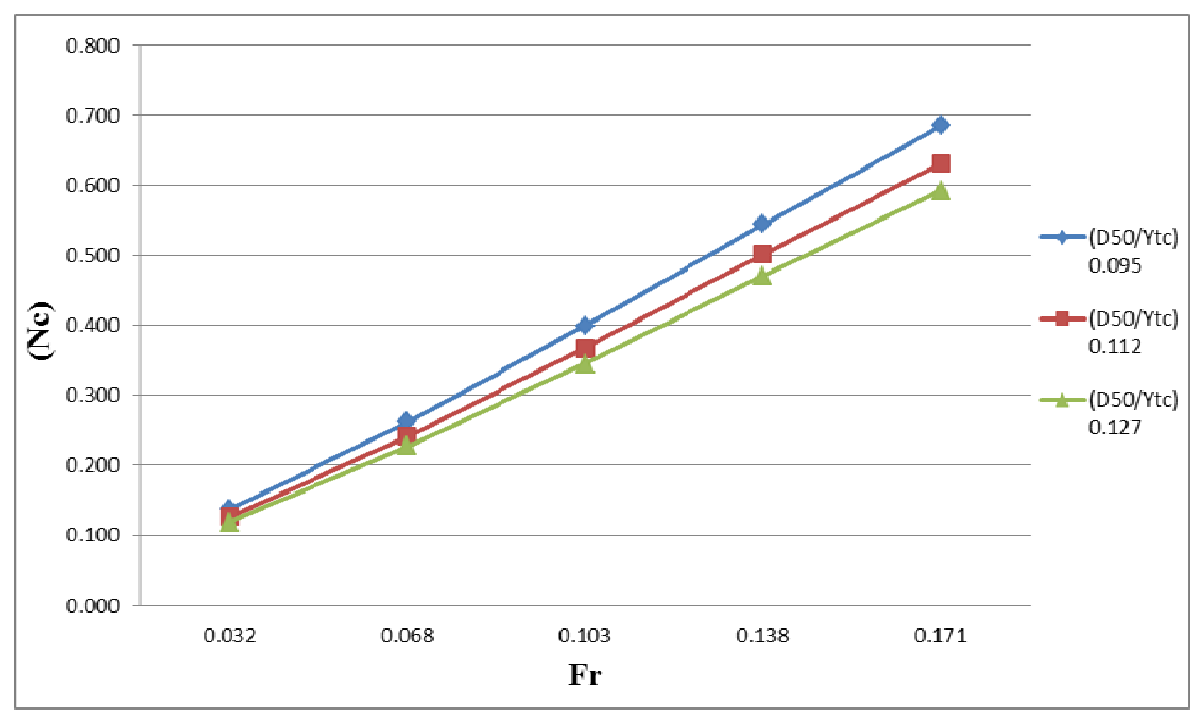

Figure 14: Comparison of the ripraps stability (Nc), groin with the length of 40m and the wing length of 24\% for different (D50/Yc)

\section{Examination of velocity, shear stress, and ripraps stability for $60 \mathrm{~m}$ groin length wing length of $12 \%$ of} the useful flume width

Froude number rise from 0.032 to 0.171 leads to increases in average flow velocity and also flow velocity at the T-shaped groin nose, from 0.031 to $0.167 \mathrm{~ms}^{-1}$ and from 0.035 to $0.185 \mathrm{~ms}^{-1}$, respectively. Such results are presented in the Table (6) and diagram of the figures (15) and (16). By comparing the results of the velocity, it can be understood that the velocity in the groin nose has had 8.6 percent average increase. Besides, Froude number rise from 0.032 to 0.171 also increases the average shear stress and the shear stress near the T-shaped groin nose as 0.01 to $0.278 \mathrm{Nm}^{-2}$ and 0.011 to $0.318 \mathrm{Nm}^{-2}$, respectively. Such increase in Froude number also increases $\mathrm{Nc}$ index from 0.137 to $0.724,0.126$ to 0.667 and 0.119 to 0.626 for $9.5,11.2$ and 12.7 mm diameter ripraps, respectively (Figure 17).

Table 6: Hydraulic and stability results for the groin with the length of 60 and the width of 12 percent

\begin{tabular}{|c|c|c|c|c|c|c|c|}
\hline \multicolumn{3}{|c|}{$\mathrm{D} 50 / Y_{t c}$} & \multicolumn{2}{|c|}{ The shear stress (واحد) } & \multicolumn{2}{|c|}{ Velocity $(\mathrm{m} / \mathrm{s})$} & \multirow[t]{2}{*}{$\mathrm{Fr}$} \\
\hline 0.127 & 0.112 & 0.095 & Average & $\begin{array}{l}\text { The groin } \\
\text { nose }\end{array}$ & Average & $\begin{array}{l}\text { The groin } \\
\text { nose }\end{array}$ & \\
\hline 0.119 & 0.126 & 0.137 & 0.01 & 0.011 & 0.031 & 0.035 & 0.032 \\
\hline 0.237 & 0.252 & 0.274 & 0.041 & 0.046 & 0.066 & 0.07 & 0.068 \\
\hline 0.362 & 0.386 & 0.419 & 0.096 & 0.107 & 0.102 & 0.107 & 0.103 \\
\hline 0.494 & 0.526 & 0.572 & 0.175 & 0.2 & 0.134 & 0.146 & 0.138 \\
\hline 0.626 & 0.667 & 0.724 & 0.278 & 0.318 & 0.167 & 0.185 & 0.171 \\
\hline
\end{tabular}




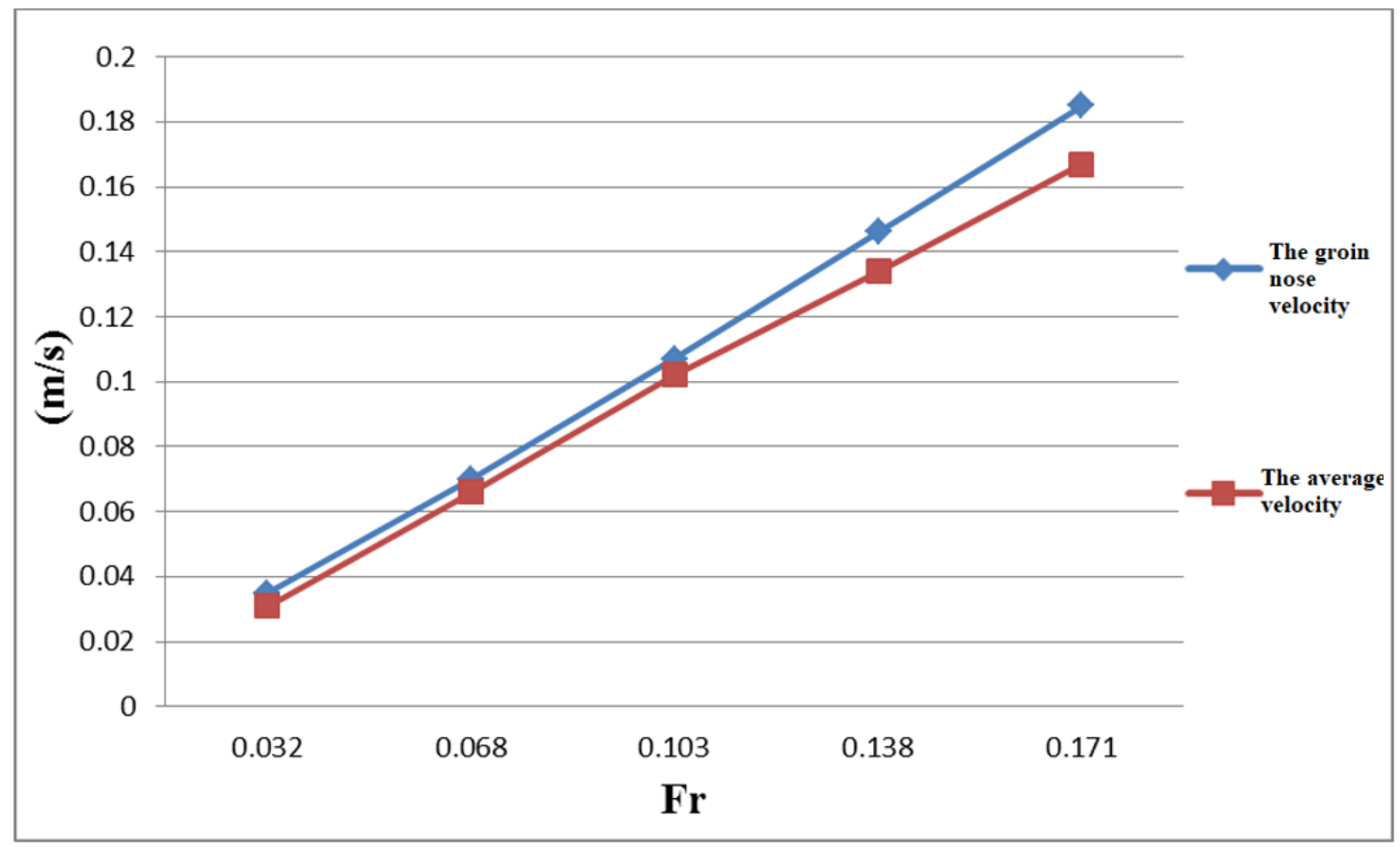

Figure 15: Groin nose and average velocity changes with Fr. for $60 \mathrm{~m}$ groin length and wing length of $12 \%$

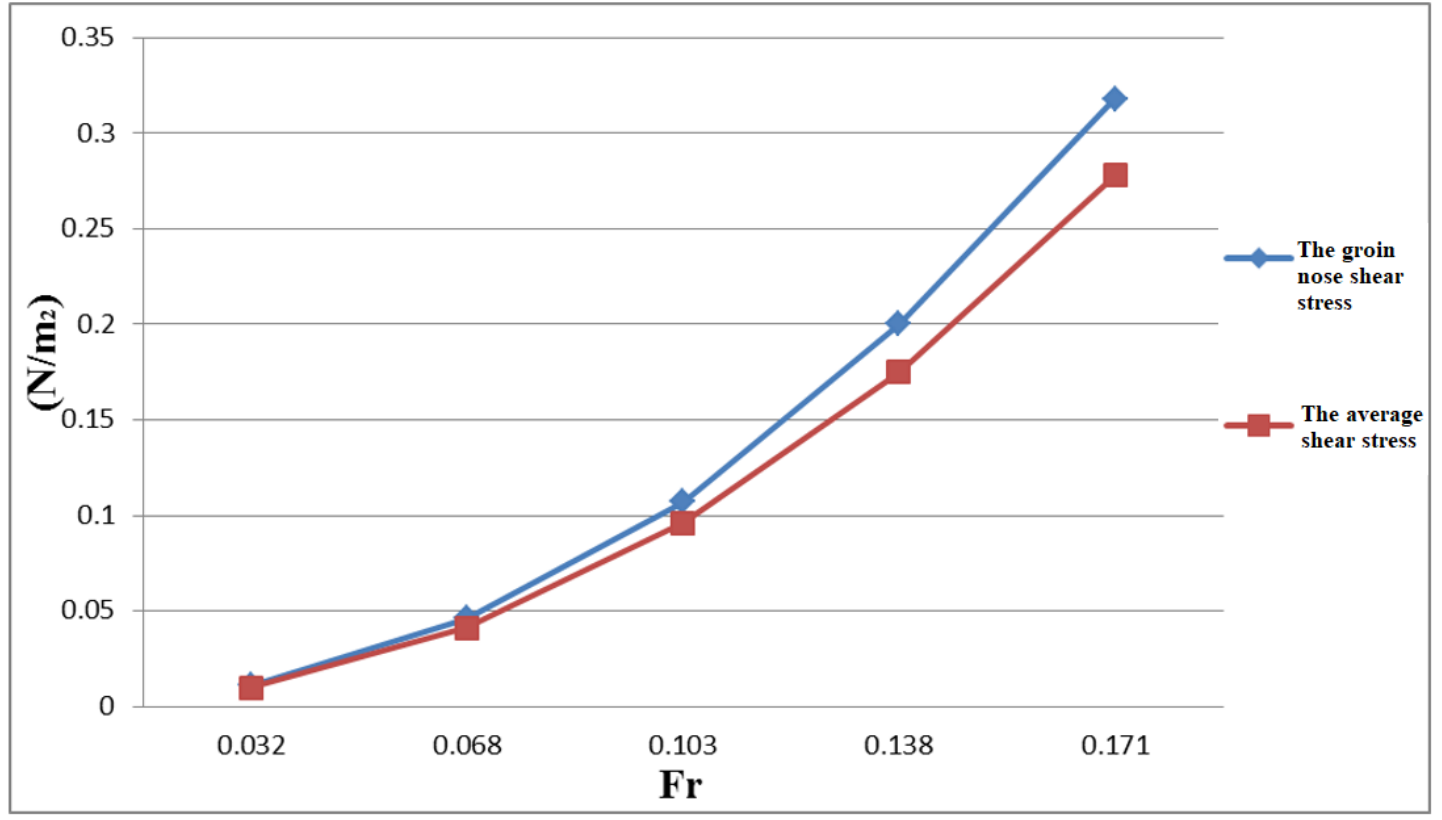

Figure 16: Groin nose and average shear stress changes with Fr. for $60 \mathrm{~m}$ groin length and wing length of $12 \%$ 


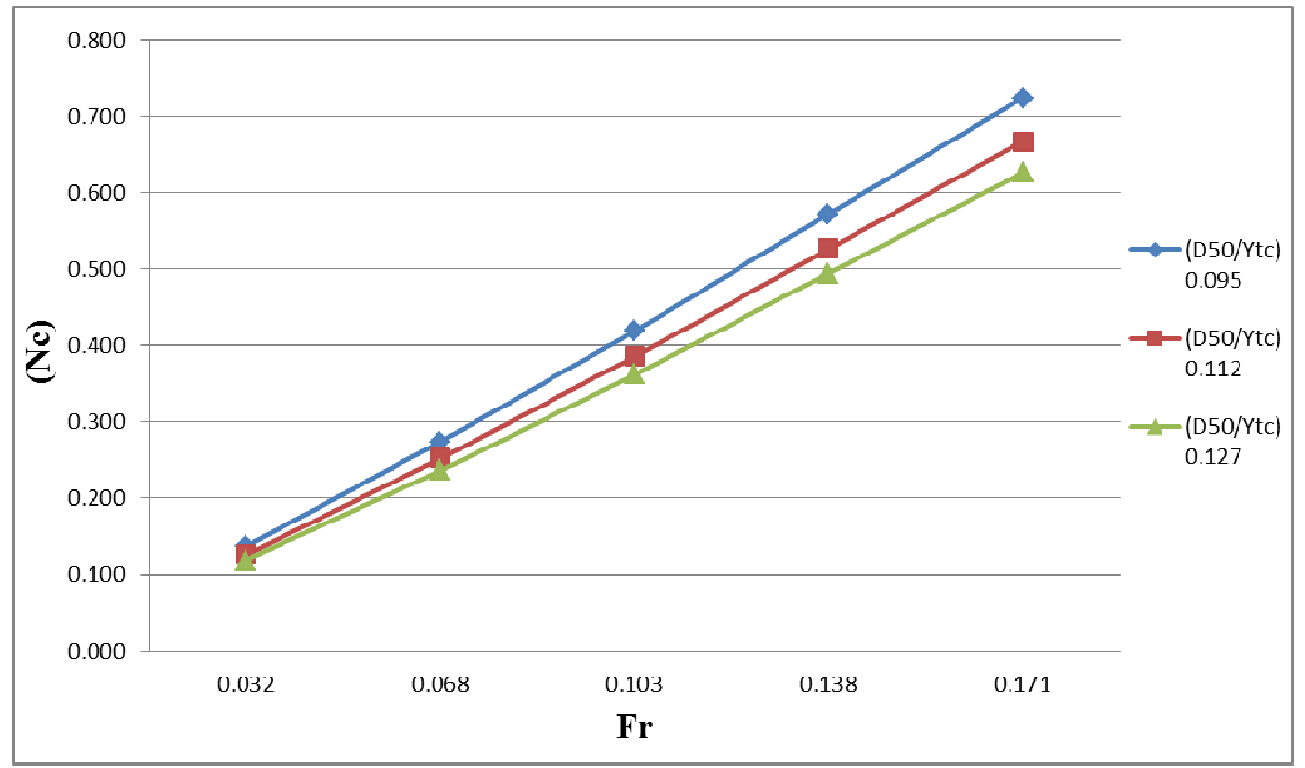

Figure 17: Comparison of the ripraps stability $(\mathrm{Nc})$, groin with the length of $60 \mathrm{~m}$ and the wing length of $12 \%$ for different (D50/Yc)

6. Examination of velocity, shear stress, and ripraps stability forgroin length of 60 and the wing length of $24 \%$ of the useful flume width

As shown in Table (7) and Figures (18) and (19), Froude number changes from 0.032 to 0.171 , rises average flow velocity from 0.031 to $0.167 \mathrm{~ms}^{-1}$ and increases flow velocity near the T-shaped groin nose from 0.035 to $0.176 \mathrm{~ms}^{-1}$. Such increasesalso changes average shear stress from 0.01 to $0.278 \mathrm{Nm}^{-2}$ and shear stress near the Tshaped groin nose from 0.011 to $0.29 \mathrm{Nm}^{-2}$. On the other hand this increase in Froude number rises Nc index as 0.137 to $0.689,0.126$ to 0.635 and 0.119 to 0.596 for riprap with $9.5 \mathrm{~mm}, 11.2 \mathrm{~mm}$ and 12.7 diameter, leading to the ripraps stability reduction. Also, by the increase of the riprap particles diameter from $9.5 \mathrm{~mm}$ to $12.7 \mathrm{~mm}$ a 13.5 percent decrease in index $(\mathrm{Nc})$, indicating ripraps stability reduction with diameter decrease.

Table 7: Hydraulic and stability results for the groin with the length of 60 and the width of 24 percent

\begin{tabular}{|l|l|l|l|l|l|l|l|}
\hline \multicolumn{3}{|c|}{$\mathrm{D} 50 / Y_{t c}$} & \multicolumn{2}{l|}{ The shear stress (N/) } & \multicolumn{2}{l|}{ Velocity(m/s) } & Fr \\
\cline { 1 - 6 } & 0.112 & 0.095 & Average & $\begin{array}{l}\text { The groin } \\
\text { nose }\end{array}$ & Average & $\begin{array}{l}\text { The groin } \\
\text { nose }\end{array}$ & \\
\hline 0.119 & 0.126 & 0.137 & 0.01 & 0.011 & 0.031 & 0.035 & 0.032 \\
\hline 0.230 & 0.245 & 0.266 & 0.041 & 0.043 & 0.066 & 0.068 & 0.068 \\
\hline 0.352 & 0.375 & 0.407 & 0.096 & 0.101 & 0.102 & 0.104 & 0.103 \\
\hline 0.477 & 0.508 & 0.552 & 0.175 & 0.185 & 0.134 & 0.141 & 0.138 \\
\hline 0.596 & 0.635 & 0.689 & 0.278 & 0.29 & 0.167 & 0.176 & 0.171 \\
\hline
\end{tabular}




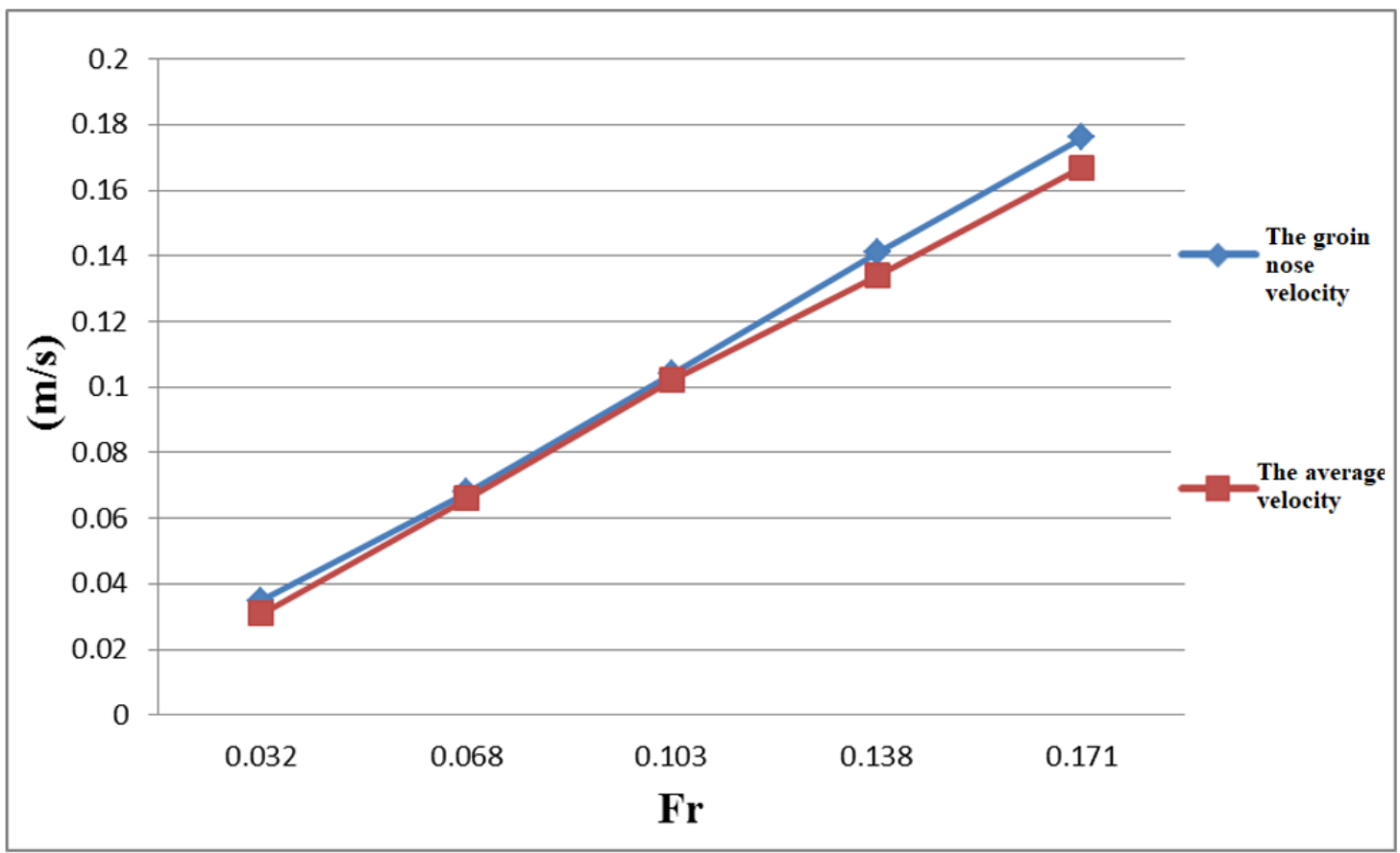

Figure 18: Groin nose and average velocity changes with Fr. for $60 \mathrm{~m}$ groin length and wing length of $24 \%$

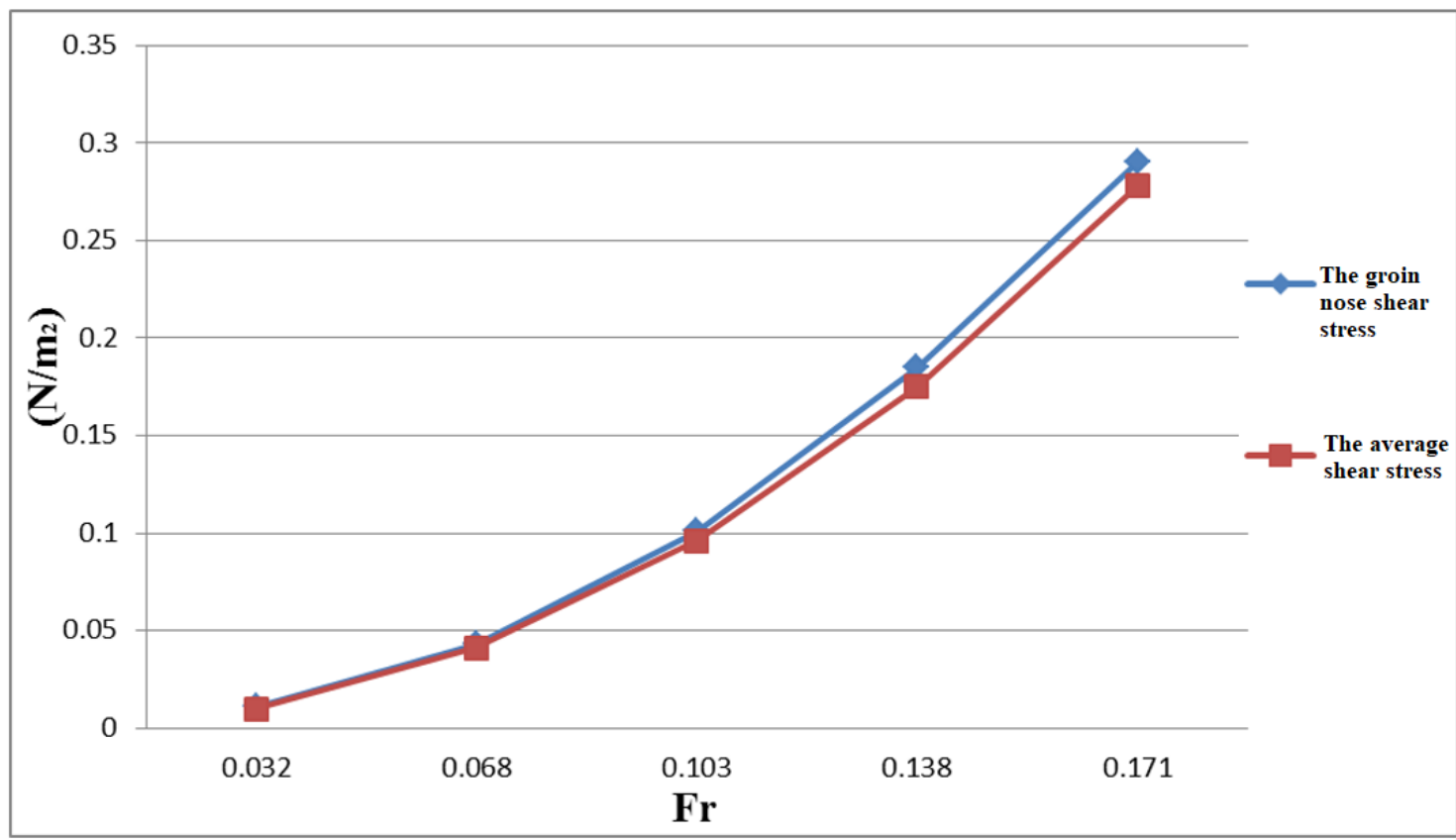

Figure 19: Groin nose and average shear stress changes with Fr. for $60 \mathrm{~m}$ groin length andWing length of $24 \%$ 


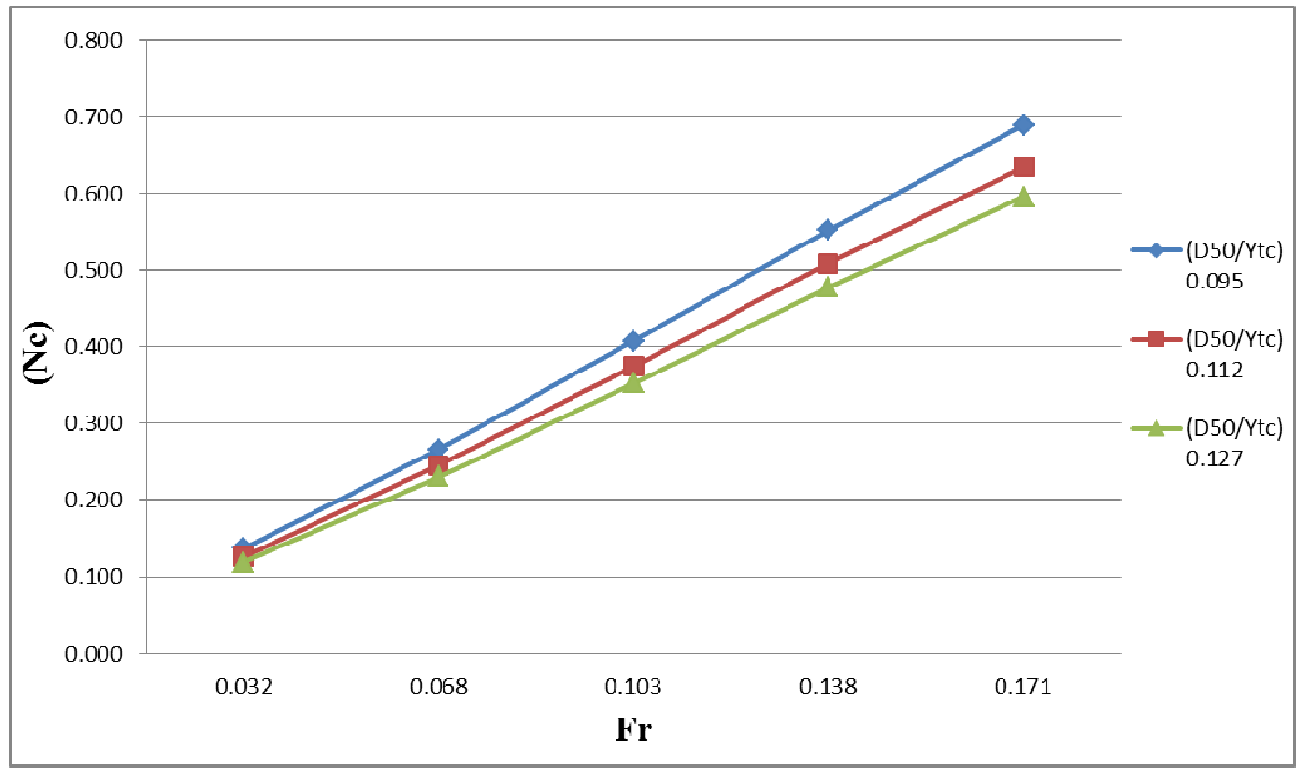

Figure 20: Comparison of the ripraps stability $(\mathrm{Nc})$, groin with the length of $60 \mathrm{~m}$ and the wing length of $24 \%$ for different (D50/Yc)

\section{Effect of groin length and wing length on the velocity and stability of the ripraps}

According to Figure (21), it can be concluded that there is no significant change in the velocity of the groin nose with the increase of the groin length. Regarding that the groin ripraps stability has a direct relationship with flow velocity so, with the increase of the groin length, there will be no significant change in the riprap stability. On the other hand, increasing groin wing length, reduces velocity will in the groin nose (Figure 22).

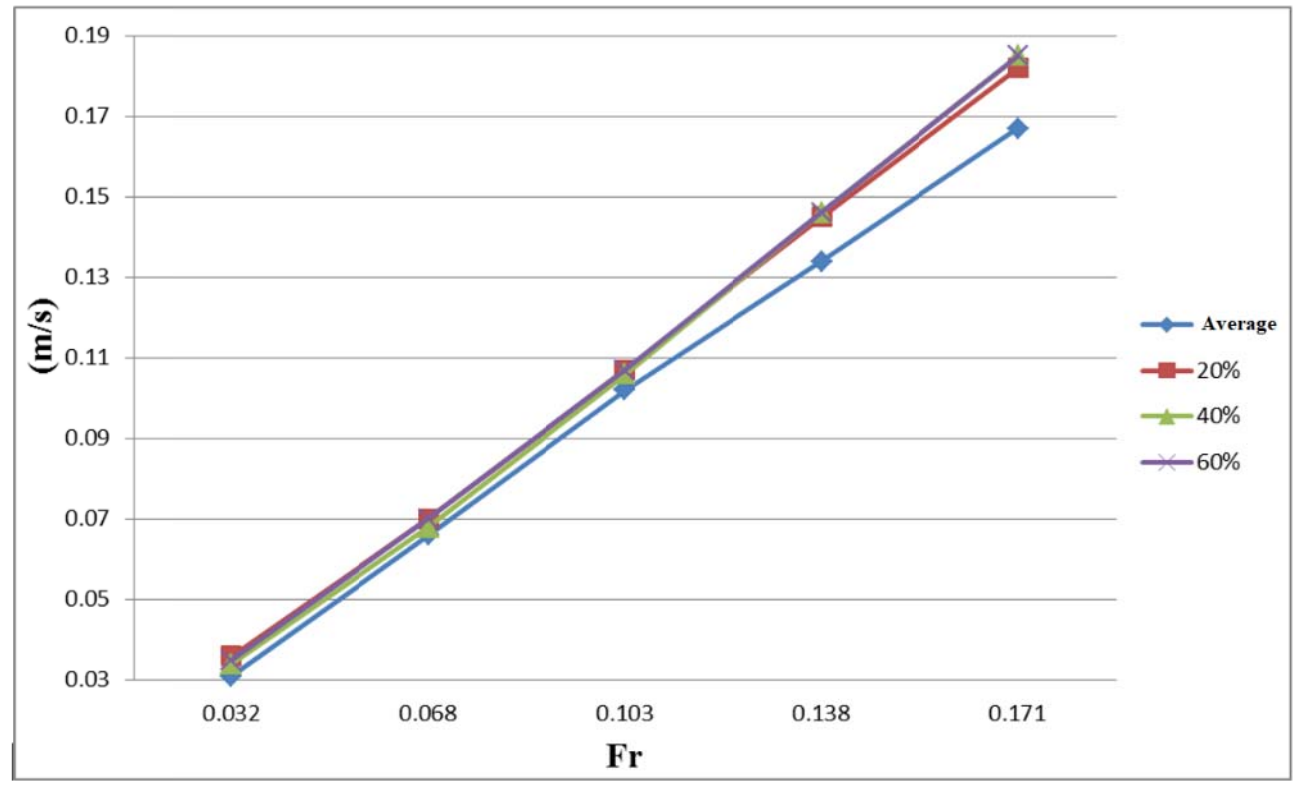

Figure 21: Comparison of velocity in the groin with different lengths and fixed wing lengths 


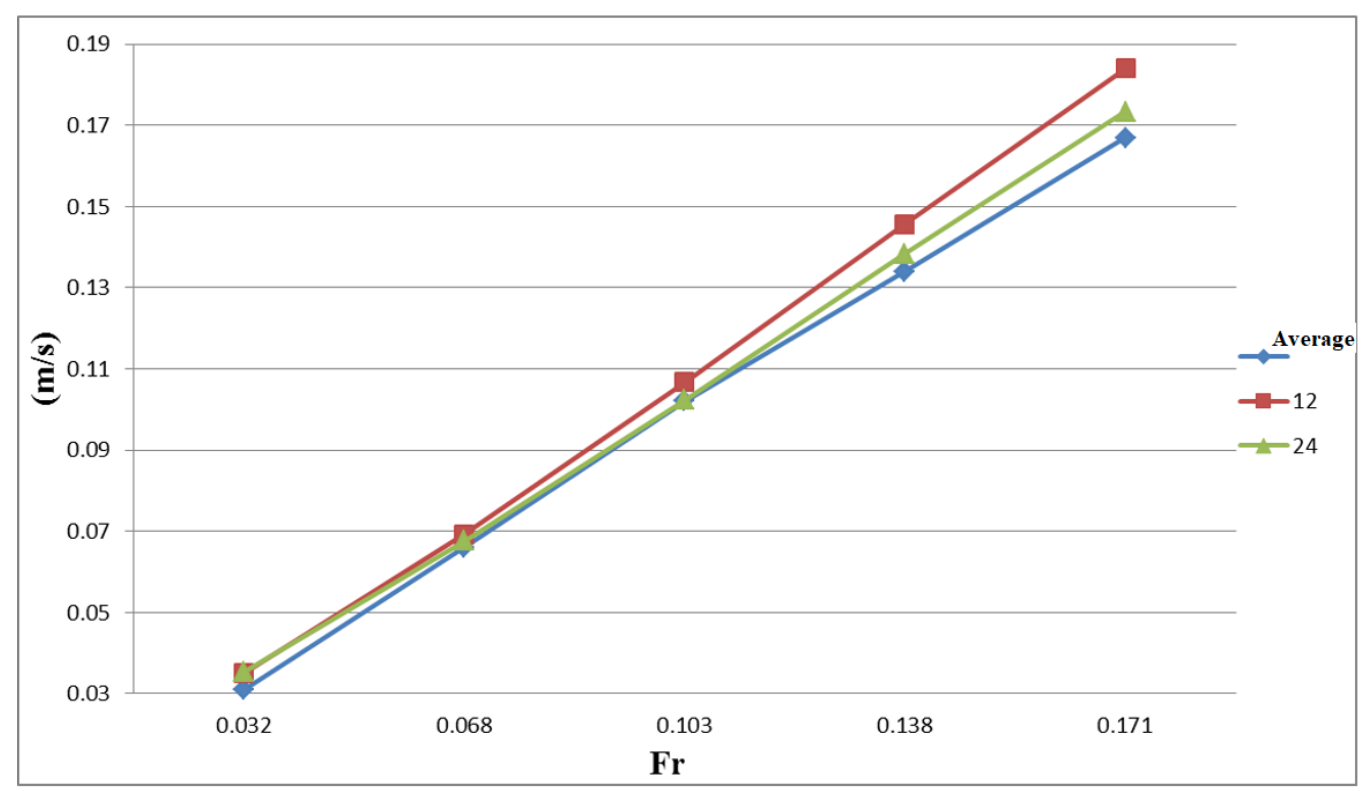

Figure 22: Diagram of the velocity comparison in the groin with different wing lengths and fixed lengths

Comparison of the simulation results with the physical model

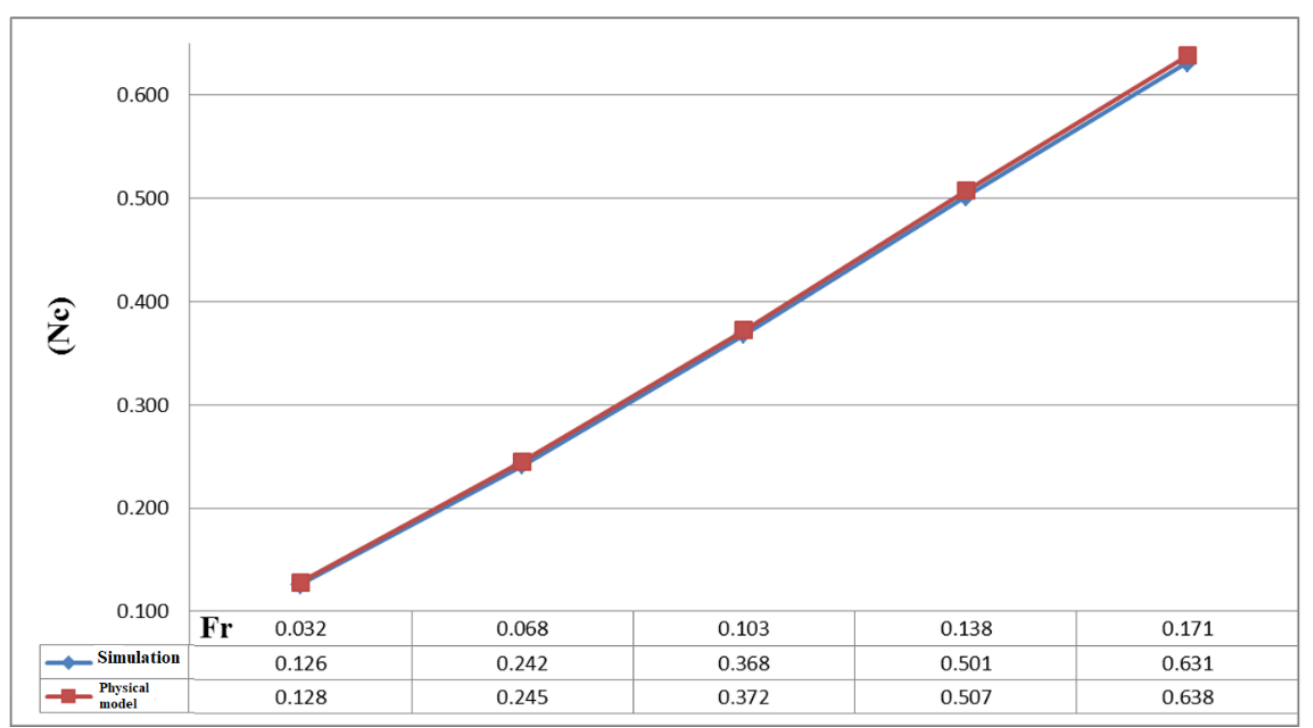

Figure 23: Comparison of the results of simulation results with the physical model

Comparison of simulation results using CCHE2D software with the physical model is shown in Figure (23).To create a similar situation comparison by the groin with the length of 40 and the wing length of 24 percent useful width of the river was done. According to the results, it can be observed that simulation results are very close to the physical model and have an average of 1.17 percent difference.

\section{Conclusions}

With the increase of Froude number, flow velocity and shear stress ingroin nose has increased leading to the rise of the index $(\mathrm{Nc})$ consequently reducing ripraps stability. On the other hand, with the increase of riprap particles diameter from $9.5 \mathrm{~mm}$ to $12.7 \mathrm{~mm}$ a $13.5 \%$ reduction in index $(\mathrm{Nc})$ has been observed indicating the increase of the ripraps stability with diameter increase. There will be no significant change in the velocity of the groin nose with the increase of the groin length. Regarding that groin ripraps stability has a direct relationship with flow velocity,therefore by increasing the groin length, there will be no significant change in the riprap stability. With the increase of the groin wing length,velocity will be reduced in groin nose. This reduction is more obvious in the high downs. According to the direct relationship between groin ripraps stability and flow velocity, it can be concluded that with the increase of groin wing length, ripraps stability will increase.The simulation results were very close to those of the physical model with an average of $1.17 \%$ difference. This comparison shows that CCHE2D software can be used for groins simulationand ripraps stability analysis with high precision. 


\section{References}

[1] Abbasi, S. and Kamanbedast, A.A. (2012) Investigation of Effect of Changes in Dimension and Hydraulic of Stepped Spillways for Maximization Energy Dissipation, World Applied Sciences Journal 18 (2): 261-267, ISSN 1818-4952.

[2] Ali Naqi A. Behbahanihadi. (1383), check the hydraulic conditions in the intake with 90 and 75 degree oblique angle using physical models, irrigation engineering master's thesis, ShaheidChamran University.

[3] Azarang, 1388, review the terms of flow and sediment in the range of Ahvaz Karoon River using mathematical models CCHE1D, Published master's thesis / Islamic Azad University, Science and Research Branch of Khuzestan.

[4] Charlton, F. G. (1982). River Stabilization and Training in Gravel-Bed Rivers, in Hey, R. D.,Bathurst,J. C., Thorne, C. R. (Eds). Gravel-Bed Rivers: Fluvial Processes, Engineering and Management. John Wiley and Sons, Chichester.

[5] Chiew YM, 1995. Mechanics of riprap failure at bridge piers. Journal of Hydraulic Engineering, ASCE 121(9), 635-643.

[6] EsmaeelinejadMuhammad. (1381), check the hydraulic laboratory using micromodel Hamidieh inflow basin diversion dam, irrigation facilities engineering master's thesis, ShaheidChamran University.

[7] Lagasse PF, Zevenbergen LW, Schall JD and Cooper PE, 2001. Bridge scour and stream instability countermeasures. Rep. No. FHWA-NH1-01-003, Hydraulic Engineering Circular N ${ }^{\circ}$ 23(HEC-23).

[8] Khezri race, Zahir, keys, H. (1389), sedimentation in the reservoir simulation model using a mathematical model Grsha CCHE2D, Iranian Hydraulic Conference.

[9] Roughanian, Sina, (1389), check the hydraulic properties of Karun river flow by using CCHE2D, Master's Thesis, Islamic Azad University, Science and Research Branch of Khuzestan.

[10] Kamanbedast, Amir Abbas, (1389), Handbook Application CCHE2D, Islamic Azad University of Ahvaz.

[11] Gharibvand, R., Heidarnejad, M., Kashkouli, H., Hasoonizadeh, H., Kamanbedast, A.A. (2016). An experimental study into hydraulic coefficient in trapezoidal labyrinth weir and piano key weir. Fresen. Environ. Bull., 25(12), 5590-5598.

[12] Kamanbedast, A., Gholizade, B. (2012) .The study of siphon spillway Hydraulic by Modeling (physical an software), Journal of Applied sciences Research, 8(5): 2548-2553, 2012.

[13] Kamanbedast, A. (2012) The Investigation of Discharge Coefficient for the Morning GlorySpillway Using Artificial Neural Network. World Applied Sciences Journal 17: 913-918.

[14] Kamanbedast, A.A., Mousavi, S.R., Barati, A. (2014). The effect of number and angle of guide piers on hydraulic behavior of morning glory spillway with square inlet. Advances in Environmental Biology, 2377-2384.

[15] Kamanbedast, and Beheshti (1390), numerical analysis, hydraulic parameters in the river, the first International Conference and the National Conference of dams and hydroelectric plants

[16] Niknam, Ali, (1391), Deposited in Dez reservoir simulation model using the software CCHE2D, Iran Water Resources Management Conference - Surrey.

[17] Brian D. Barkdoll, Robert Ettema, Members, ASVE, and A. JoobOdgaard, Fellow, ASCE (1999), "Sediment Control At Lateral Divertion: Limits and Enhacements To Vane Use", Journal of Hydraulic Engineering, ASCE, Vol.122, No. 7. Pp.862-870

[18] Davinroy, Robert D. (1999), "River Replication", Journal of Civil Engineering, Vol., No., pp. 60-63

[19] Fares, Y.R., Herbertson, J.G. (1993), "Behaviour of Flow in a Channel Bend a Side Overflow (flood relief) Channel", Journal of Hydraulic Research, IAHR, Vol. 31, No. 3, pp. 383-402.

[20] Hussein, A.S.A. and Smith, K.V.H. (1986), "Flow and Bed Deviation Angle in Curved Open Channels", Journal of Hydraulic Research, Vol. 24, No. 2, pp. 93-108.

[21] Johnson, P.A., Hey, R.D., Tessier, M., and Rosgen,D.L. 2001.use of vanes for control of scour at vertical wall abutments, journal of Hydraulic Engineering, ASCE, 127:9. 772-778.

[22] Marelius, F., Sinha, S.K. (1998), "Experimental Investigation of Flow Past Submerged Vanes" Journal of Hydraulic Engineering, ASCE, Vol. 124, No. 5, pp. 542-545

[23] Nakato, T., Kennedy, J,F. and Bauerly, D. (1990), "Pump-Station Intake - Shoaling Control with Submerged Vanes", Journal of Hydraulic Engineering, ASCE, Vol. 116, No. 1, pp. 119-128.

[24] Nakato, T.,Ogden, F.L. (1998), "Sediment control at Water Intakes Along Sand- Bed Rivers", Journal of Hydraulic Engineering, ASCE, Vol. 124, No. 6, pp. 589-596.

[25] Neill, C.R. Evans, B.J. (1997), "Disusion by Sediment Control at Water Intake", Journal of Hydraulic Engineering, ASCE, Vol. 122, No. 7, pp. 670-671.

[26] Novak, P. and Cabelka, J. (1981)"Models in Hydraulic Engineering", Pitman Advanced Publishing Program, 459 pages.

[27] Odgaard, A.J. and Wang, Y. (1991), "Sediment Management with Submerged Vanes", I: Theory, Journal of Hydraulic Engineering, ASCE, Vol. 117, No.3, pp. 267-283.

[28] Odgaard, A.J. and Wang, Y. (1991), "Sediment Management with Submerged Vanes", II: Application, Journal of Hydraulic Engineering, ASCE, Vol. 117, No.3, pp. 284-301.

[29] Richardson, E. V., Stevens, M. A., and Simons, D, B. (1975). The design of spurs for river training. 16 IAHR Congress, San Paolo, Brazil, Vol. B(47), 382-388

[30] Taebi, and Shafaie, (1388), the numerical simulation of flow in a 90 degree arc of the eighth international seminar on river engineering model CCHE2D, ShaheidChamran University.

[31] Unger J and Hager WH, 2006. Riprap failure at circular bridge piers. Journal of Hydraulic. Engineering, ASCE 132(4):354-362.

[32] Zhang, Y. (2005), CCHE2D-GUI - Graphical User Interface for the CCHE2D Model, User's Manual - Version 2.2, Technical Report No. NCCHE-TR-2005- 03, The University of Mississippi. 